Document downloaded from:

http://hdl.handle.net/10251/104555

This paper must be cited as:

Harby, K.; Chiva, S.; Muñoz-Cobo, JL. (2017). Modelling and experimental investigation of horizontal buoyant gas jets injected into stagnant uniform ambient liquid. International Journal of Multiphase Flow. 93:33-47. doi:10.1016/j.ijmultiphaseflow.2017.03.008

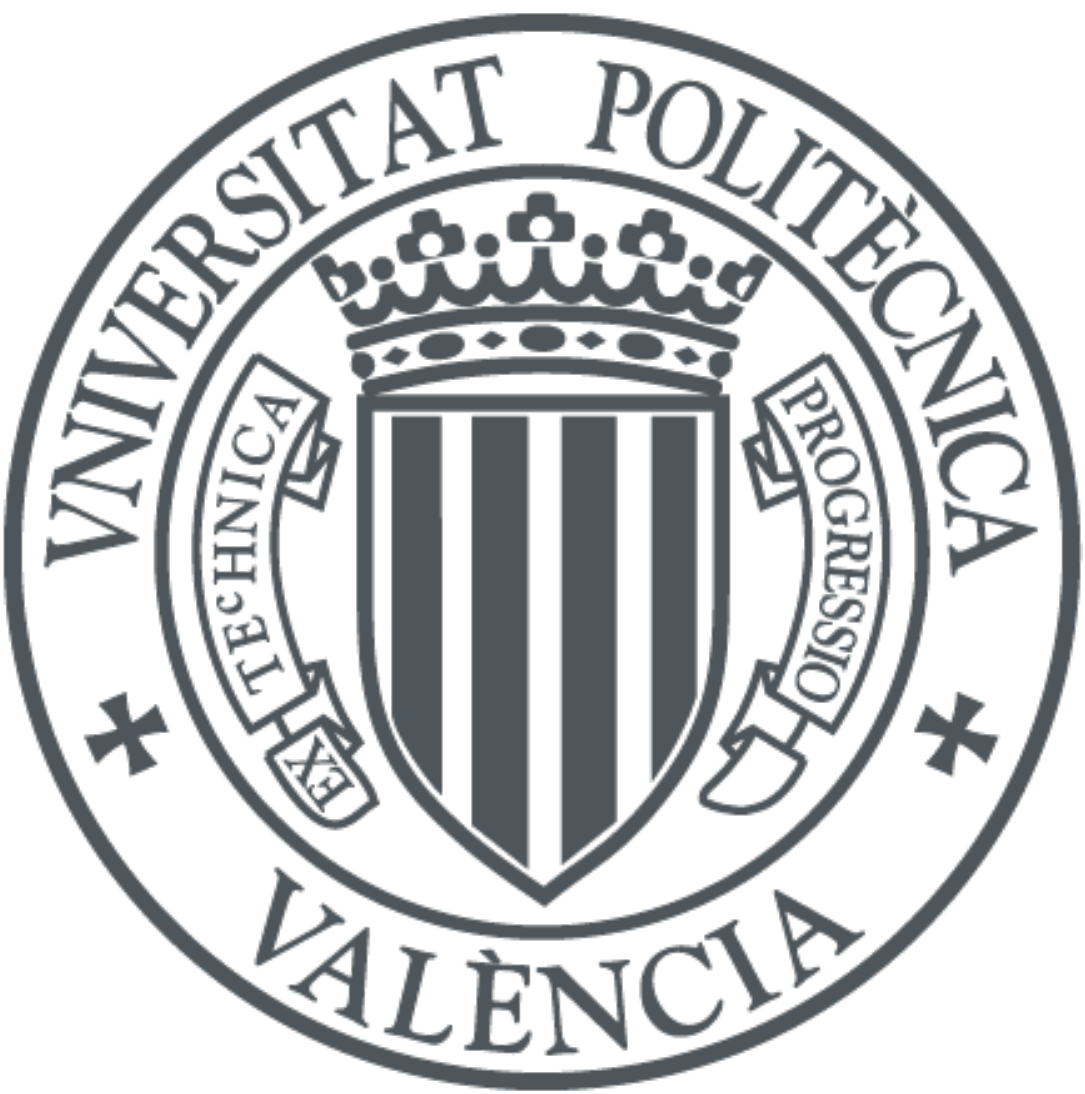

The final publication is available at

https://doi.org/10.1016/j.jimultiphaseflow.2017.03.008

Copyright Elsevier

Additional Information 


\title{
Modelling and experimental investigation of horizontal buoyant gas jets injected into stagnant uniform ambient liquid
}

\author{
K. Harby ${ }^{a, c}$, S. Chiva ${ }^{b}$ J.L Muñoz-Cobo ${ }^{a,}$, \\ aDepartment of Chemical and Nuclear Engineering, Universidad Politécnica de Valencia, PO Box 22012, \\ 46071 Valencia, Spain. \\ ${ }^{\mathrm{b}}$ Department of Mechanical Engineering and Construction, Fluid Mechanics Area, Universitat Jaume I, \\ Campus del Riu Sec 12080, Castello, Spain. \\ ${ }^{\mathrm{c}}$ Mechanical Power Engineering and Energy Department, Faculty of Engineering, Minia University, \\ 61519, Minia, Egypt \\ * Corresponding author: Tel.: +34 963877631; fax: +34 \\ Email: jlcobos@iqn.upv.es
}

\begin{abstract}
In this article, an experimental and theoretical study on the buoyant non-condensable gas jet that is injected horizontally into a high-density liquid ambient at different initial conditions is performed. Direct and instantaneous global measurements of the interface were performed using a high-speed photography. The position and motion of the entire gas jet were captured by a high-velocity camera and the images were processed, averaged and analyzed to extract the jet parameters and interface position. In the mathematical model, the rate of entrainment is assumed to be a function of the jet centerline velocity, the ratio of the mean jet and the ambient densities, while the entrainment coefficient depends on the local Froude number at the jet region. An interfacial shear stress acting at the interface between the jet flow and the water ambient in the opposed direction to the main jet momentum flux is considered. The results showed that the model is able to accurately predict the jet parameters: trajectory, spread,
\end{abstract}


jet angles and penetration lengths as well as the jet regimes. An overall good agreement was obtained between the simulation and experimental results over a large range of Froude numbers and jet diameters. The developed model has proven to be an adequate tool to predict the different jet parameters.

Keywords: Gas injection; Modeling; Buoyant gas jets; Non-Boussinesq; Experimental; Entrainment.

\begin{tabular}{|c|c|c|c|}
\hline \multicolumn{4}{|c|}{ Nomenclature } \\
\hline $\mathrm{A}_{\mathrm{N}}$ & Nozzle area $\left(\mathrm{m}^{2}\right)$ & $\mathrm{M}_{0}$ & Initial momentum flux at the injector exit $(\mathrm{N})$ \\
\hline $\mathrm{b}$ & Jet half width (m) & $\mathrm{M}_{\mathrm{x}}$ & Jet momentum flux in $\mathrm{x}$-direction $(\mathrm{N} / \mathrm{m})$ \\
\hline $\mathrm{B}_{0}$ & Initial buoyancy flux $(\mathrm{N})$ & $\mathrm{M}_{\mathrm{y}}$ & Jet momentum flux in $\mathrm{y}$-direction $(\mathrm{N} / \mathrm{m})$ \\
\hline$d_{N}$ & Nozzle diameter $(\mathrm{m})$ & $\mathrm{Q}_{0}$ & Initial volume flux $\left(\mathrm{m}^{3} / \mathrm{s}\right)$ \\
\hline E & Local rate of entrainment $(\mathrm{kg} / \mathrm{s})$ & $\alpha$ & Local coefficient of entrainment (-) \\
\hline $\mathrm{E}_{\text {buoy }}$ & Entrainment rate due to buoyancy $(\mathrm{kg} / \mathrm{s})$ & $\alpha_{\mathrm{j}}$ & Pure jet entrainment coefficient (-) \\
\hline $\mathrm{E}_{\mathrm{mom}}$ & Entrainment rate due to momentum $(\mathrm{kg} / \mathrm{s})$ & $\alpha_{\mathrm{p}}$ & Pure plume entrainment coefficient (-) \\
\hline $\mathrm{Fr}_{0}$ & Initial Froude number at nozzle exit (-) & $\dot{m}_{\mathrm{d}}$ & Water droplets mass flow rate per unit length $(\mathrm{kg} / \mathrm{m} \mathrm{s})$ \\
\hline $\mathrm{Fr}_{\mathrm{s}}$ & Local Froude number (-) & $\tau_{\mathrm{i}}$ & Interfacial shear stress $(\mathrm{N} / \mathrm{m})$ \\
\hline $\mathrm{u}_{0}$ & Initial jet velocity at the nozzle exit (m/s) & $\Theta$ & Local angle of inclination of the jet (degree) \\
\hline $\mathrm{u}_{\mathrm{d}}$ & Water droplets velocity (m/s) & $\rho_{\mathrm{a}}$ & Water ambient density $\left(\mathrm{kg} / \mathrm{m}^{3}\right)$ \\
\hline $\mathrm{u}_{\mathrm{e}}$ & Entrainment liquid velocity $(\mathrm{m} / \mathrm{s})$ & $\rho_{\mathrm{g}}$ & Air jet density $\left(\mathrm{kg} / \mathrm{m}^{3}\right)$ \\
\hline $\mathrm{L}_{\mathrm{b}}$ & Buoyant jet penetration length (m) & $\rho_{\mathrm{w}}$ & Density of water $\left(\mathrm{kg} / \mathrm{m}^{3}\right)$ \\
\hline $\mathrm{L}_{\mathrm{m}}$ & Momentum jet penetration length (m) & 0 & Initial \\
\hline $\mathrm{L}_{\mathrm{Q}}$ & Geometric length, $\sqrt{\mathrm{A}_{\mathrm{N}}}(\mathrm{m})$ & a & Air \\
\hline $\mathrm{L}_{\mathrm{s}}$ & Characteristic length scale (-) & $\mathrm{N}$ & Nozzle exit \\
\hline $\mathrm{L}_{\mathrm{b}}$ & Buoyant jet penetration length (m) & $\mathrm{w}$ & Water \\
\hline
\end{tabular}




\section{Introduction}

Turbulent buoyant jets form a complex multiphase system, which have a great interest in many environment and industrial applications. A buoyant jet is formed when a continuous stream of low-density fluid with large momentum originating from a nozzle enters into a liquid medium with bigger density. Depending on the initial jet momentum and the density difference between the two fluids, the jet breaks up into a train of bubbles, either immediately at the nozzle exit or at some distance downstream. Three general groups of factors govern the buoyant jet behavior they are: (i) jet parameters, (ii) environmental parameters and (iii) geometrical factors. The first group includes the initial jet velocity, the turbulence level, the jet mass, momentum and the density deficit between the jet and the ambient fluid. The second group of variables includes the ambient fluid parameters, such as turbulence level, currents, and density stratification. These factors usually begin to influence the jet behavior at some distance from the orifice. Finally, the geometrical factors include the depth of submergence of the jet, the jet shape, its orientation and proximity to solid boundaries or to the free surface.

The considerable research activity in the area of buoyant jets over the past 50 years has resulted in different experimental studies and a number of different models that mathematically describe the jet flow path. Different experimental investigations have been conducted in the past few decades on the turbulent jets and the results provided support for the mathematical modeling approach (Liang et al., 2016; Taib, 2015; Harby 2012; Francis et al., 2014).

The mathematical models based on the jet behavior existing in the literature can be classified mainly into three different categories: integral models, length-scale models, 
and models that use a combination of both length-scales and integral techniques. Integral models which are based on the conservation equations of mass, momentum and buoyancy fluxes are the most common ones; they are widely used in engineering practice for the prediction of characteristics for these buoyant jet discharges (Ficher et al., 1979). Most of these models consider only the mean mass and momentum fluxes in the set of conservation equations. Hence, they can be referred to as first-order integral models. However, few experimental data and calculations on the buoyant jet with large density variations can be found in the literature. Most of the researches were carried out for small density variation when the Boussinesq approximation is valid and the jet is discharged vertically (Harby et al., 2014a). There is still very little experimental data and calculations to understand well these flows (Harby et al., 2014b).

Crapper and Baines, 1977 suggested that the upper bound of applicability of the Boussinesq approximation is that the initial fractional density difference $\Delta \rho_{0} / \rho_{\mathrm{a}}$ is 0.05 . In general, one can say that the Boussinesq approximation is valid for small initial fractional density difference, $\Delta \rho_{0} / \rho_{\mathrm{a}} \ll 1$. The non-Boussinesq plume was studied by a number of researchers (Woods, 1997; Carlotti and Hunt, 2005). Xiao et al., 2009 studied and developed a non-Boussinesq integral model for horizontal buoyant round jets with a modified entrainment hypothesis. The system of conservation equations of the integral model was solved to obtain numerical solutions in the transition region from jet-like to plume-like. They concluded that for a strongly buoyant jet the Boussinesq approximation is violated which will over-predict the mass entrainment and underestimate the buoyancy effect. This study reveals that the Boussinesq approximation is valid when the density variation is less than $10 \%$ being the entrainment assumption a key requirement for the integral model. 
The entrainment rate of a turbulent jet is defined as the ambient fluid that is mixed across the jet edge and becomes incorporated into the body of the jet. The agents of entrainment are turbulent eddies forming a mixing layer between the jet and its surroundings. This process has the effect of increasing the total jet mass flux (Houf et al., 1956). The first to incorporate the entrainment approach into a general jet model was Fan et al., 1969 which used the Eulerian integral method, in which the flow passed through a fixed control volume, and integrated the equations of motion over that control volume. Other ones, who have used this approach, are: Muellenhoff et al., 1985; Wood, 1993; Chu and Lee, 1996; Jirka, 2004.

Morton, 1965 concluded that there was an average entrainment into the jet-like flow that was proportional to the mean centerline velocity. List et al., 1979 showed that the entrainment mechanism is the same in both jets and plumes and is dominated by almost periodic large-scale motions which engulf the ambient fluid. The unmixed fluid is transported well into the turbulent fluid and mixed by the action of small eddies. Abraham, 1963 showed that the rate of expansion of a buoyant flow was independent of the type of flow (jet-like or plume-like) and with this alternative assumption proceeded to the solution. List and Imberger, 1973; Jirka and Harleman, 1979 were able to relate the two assumptions and derive the entrainment constants for the jet and the plume. Taylor, 1958; Kotsovinos, 1975; Agrawal and Prasad, 2004 suggested that for turbulent buoyant jets, the turbulent entrainment is usually parameterized by relating the inflow velocity to the mean flow in the jet body also they suggested that a substantial contribution to entrainment is made through nibbling of small scale vortices see also Mathew and Bassu 2002. 
Numerous experimental and numerical studies provided values of the entrainment rate for example Houf and Schaefer, 2008; El-Amin et al., 2010; El-Amin and Kanayama, 2009 assumed that the local rate of entrainment consisted of two components; one was the component of entrainment due to jet momentum while the other one was the component of entrainment due to buoyancy. Also, they reported that the local rate of entrainment increases as the jet leaves the momentum-dominated region and enters a region where the effects of buoyancy become more pronounced. This non-similarity of the entrainment rate along the jet trajectory has been discussed by Carazzo et al. (2006). Other authors predicted the behavior of the buoyant jet by using integral equations formulated under the assumption of axial symmetry and self-similar transverse profiles (Fisher et al., 1979; Wood, 1993; Pantokratoras). Batchelor, 1998 showed that a strong entrainment from the ambient will take place when the density ratio tends to unity $\left(\rho_{\mathrm{g}} / \rho_{\mathrm{a}} \rightarrow 1\right)$ while as the density ratio tends to zero $\left(\rho_{\mathrm{g}} / \rho_{\mathrm{a}} \rightarrow 0\right)$ the entrainment falls to zero and as the density ratio varies between the two limits there will be a smooth transition.

The horizontal buoyant jets with large density variations have not received sufficient research before, and almost no experimental data could be found in the open literature. However, submerged horizontal gas jets in liquid exhibits different flow characteristics from gas-gas flow because bubble breakup occurs in two-phase flow and the unsteady motion of the gas-liquid interface has a strong influence on the momentum transfer and the buoyancy force. Hence, it remains a challenging issue to understand well these flows, to calculate the flow structures numerically, to verify the numerical models and to measure them experimentally. 
In their efforts to understand the characteristics of submerged gas jets, past researchers have relied on point measurements such as electro-resistivity probes to separate the liquid and gas phases for study (Mori et al. 1982; Ito et al. 1991). In these techniques, the probe is placed at the measurement point for some time and is then traversed in space. The sensing element can be a singular measurement point or be composed of several measuring points capable of simultaneous measurement at multiple spatial locations. In either case, the probe itself is intrusive and only permits time-averaged whole-field measurements since the probe can only exist at one (or several) points in space at any given time. In such an unsteady and highly irregular flow field, a global measurement is preferred since instantaneous information can be obtained. An example of a global measurement is high-speed photography, which has been used in the past (McNallan and King 1982; Loth and Faeth 1989) to observe the interface, but the level of quantitative detail gathered from the recorded images was very low.

In this study, an integral numerical model was developed to predict the behavior of a horizontal gas jet injected from straight tubes into water ambient under different operating conditions. Since a major goal of this work was to study the interface motion itself, the technological limitations imposed by traditional measurement techniques were unacceptable. Thus high-speed photography was used to record the position and motions of the entire gas jet and the digital images were analyzed to extract the interface position. Thus direct and instantaneous global measurements of the interface were taken. Recorded images are a projection of the density variations seen in the test section. The gas jet parameters were obtained performing first a time-average of the recorded images followed by a careful analysis of the processed data. The model equations and a solution procedure was coded with input and graphical output routines into a MATLAB program and finally compared with the experimental data. 


\section{Model description and assumptions}

Fig. 1 shows the sketch and streamline coordinates of the developed model. The round buoyant jet starts from the origin at an angle $\Theta_{0}=0^{\circ}$ with respect to the horizontal $\mathrm{x}-$ axis and discharges into a stagnant uniform water ambient. Variables $\mathrm{s}$ and $\mathrm{r}$ are the natural coordinates, and $\theta$ is the angle of the s-axis with the horizontal direction. The parametrical coordinate (s) measures the distance along the jet axis from the origin. The initial density, velocity, and diameter of the orifice are denoted by $\rho_{g}$, $u_{0}$ and $d_{N}$ respectively. The density of the water ambient is $\rho_{\mathrm{a}}$. In addition, $u_{g, s}(\mathrm{~s}, \mathrm{r}) \approx u_{g}(s, r)$ and $\mathrm{u}_{g, r}(\mathrm{~s}, \mathrm{r})$ denote the velocity components of the curvilinear natural coordinates and $\mathrm{u}_{\mathrm{s}}$ is the centerline velocity along the s-axis. Normally the radial component is negligible in comparison with the component in the direction of the s-axis.

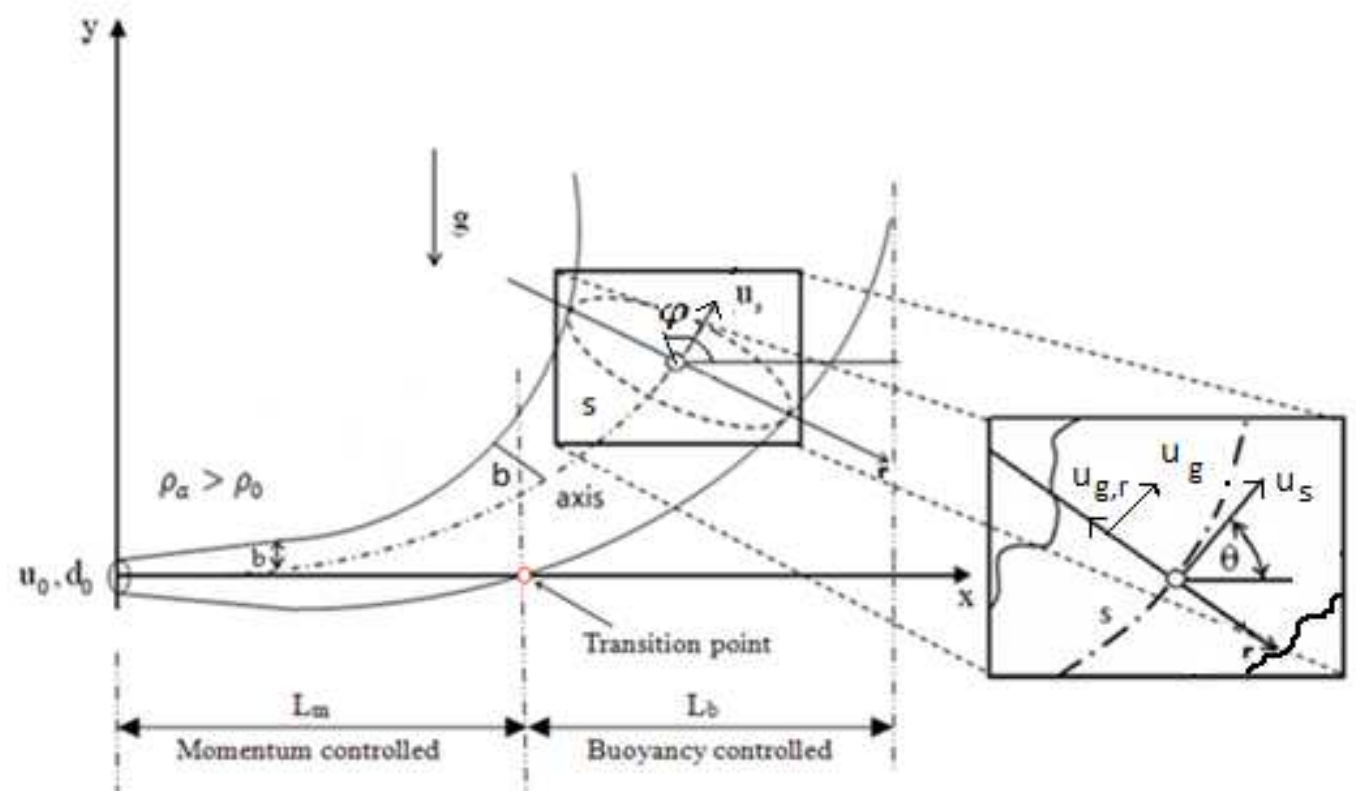

Fig. 1. Definition sketch and details of the proposed mathematical model and coordinate system of a horizontal buoyant gas jet discharged from a round orifice into a stagnant ambient 
As mentioned before, the flow of the buoyant jet contains both momentum and buoyancy fluxes. Depending on the relative importance of the inertial and buoyancy force, the flow can be classified as jet-dominated or plume-dominated. Therefore, the jet flow along the downstream distance (s) can be divided into (i) momentum jet regime within a length $\mathrm{L}_{m}$ from the nozzle exit region and (ii) buoyant jet regime within a length $\mathrm{L}_{b}$ measured from the end section of the momentum region, see Fig. 1. In the first regime, the jet shape remains straight or is slightly diverging due to the high velocity of the jet. After the jet penetrates into the liquid, buoyancy makes the jet bend towards the free surface and the buoyant jet eventually becomes a plume. We use these two regimes in order to divide the captured image.

\subsection{Underlying model assumptions}

i. The velocity profiles are assumed to be self-similar at all cross sections normal to the jet trajectory, however the entrainment rate is not assumed to be self-similar and therefore the entrainment coefficient is not constant and can change along the jet trajectory.

ii. The sum of the static pressure plus the dynamic pressure is assumed to be uniform at a given cross section normal to the flow trajectory inside the gas jet. However it can change from one point of the trajectory to another one due to pressure losses.

iii. Longitudinal turbulent transport is small compared with latitudinal convective transport.

\subsection{Velocity profile}

To simplify the problem the usual approach is to integrate the set of conservation equations of mass and momentum across the jet assuming a time averaged mean 
velocity profile normal to the jet axis. The most common profile used by investigators is a Gaussian distribution, with no dependence on the azimuthal angle $\varphi$ coordinate (Rouse et al., 1952; Chen and Rodi, 1980; Rodi, 1982; List, 1982; Turner, 1986; Bhat and Narasimha, 1996; Agrawal and Prasad, 2003). The jet mean velocity is given by:

$$
\mathrm{u}_{\mathrm{g}}(\mathrm{s}, \mathrm{r})=\mathrm{u}_{\mathrm{s}}(\mathrm{s}) \exp \left(-\left(\frac{\mathrm{r}}{\mathrm{b}(\mathrm{s})}\right)^{2}\right)
$$

where, $b=b(s)$ is a characteristic jet half width, that change along the jet trajectory. The self-similarity of the velocity radial profile has been checked measuring the velocity distribution and computing the ratio $u_{g}(s, r) / u_{s}$ of the velocity for different distances and several Froude numbers, the conclusion is that the velocity profiles are self-similar within the experimental errors.

\subsection{Entrainment of ambient fluid}

One of the major difficulties in the turbulent two-phase jet analyses is in quantifying the rate of growth of the jet plume which comes from the entrainment rate (E) of ambient fluid into the jet. The entrainment rate value is not constant along the jet but varies as the relative buoyancy or local Froude number changes. Fig. 2 shows a suggested definition sketch for liquid entrainment to the gas jet. 


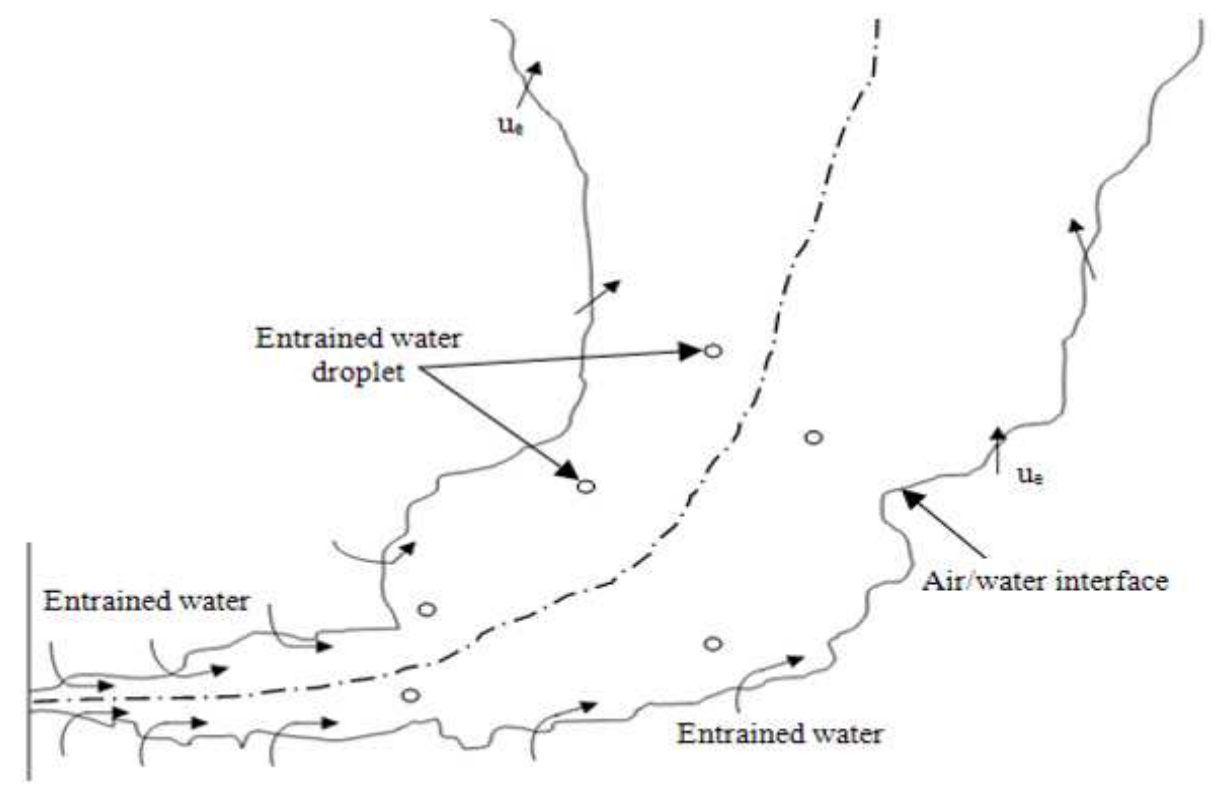

Fig. 2. Definition sketch for liquid entrainment into the main jet

According to the entrainment hypothesis, the rate of entrainment around the circumference of the jet control volume is proportional to the velocity of the entrainment at the edge and to the contact area $2 \pi \mathrm{bds}$. Therefore, the amount of ambient fluid entrained per unit time at this contact area is given by:

$$
\mathrm{dE}=2 \Pi b u_{\mathrm{e}} \rho_{\mathrm{a}} \mathrm{ds}
$$

The velocity of entrainment $\left(u_{e}\right)$ depends not only on the characteristic velocity $\left(u_{s}\right)$, but also on the square root of the local density ratio of the gas jet and the ambient fluid. Ricou and Spalding, 1961 based on their empirical measurements for an arbitrary density ratio, in order to determine the amount of water droplets entrained by the gas jet, suggested that the entrainment velocity can be calculated as follow:

$$
\mathrm{u}_{\mathrm{e}}=\alpha \sqrt{\frac{\rho_{\mathrm{g}}}{\rho_{\mathrm{a}}}} \mathrm{u}_{\mathrm{s}}
$$


where, $\alpha$ is the local entrainment coefficient. Morton [19] provides additional justification for this form of the entrainment velocity on dimensional grounds assuming that the rate of entrainment into a strongly-buoyant plume is a function of $\rho_{\mathrm{g}} / \rho_{\mathrm{a}}$ and the local Reynolds stresses which have a local magnitude proportional to $\rho_{\mathrm{g}} \mathrm{u}_{\mathrm{s}}^{2}$. The Morton assumption has been also proven by different researchers (Houf and Schefer, 2008; ElAmin et al., 2010; El-Amin and Kanayama, 2009; Steward, 1970). Equation (2) can be rewritten in the following form:

$$
\mathrm{dE}=2 \Pi b \rho_{\mathrm{a}} \alpha\left(\rho_{\mathrm{g}} / \rho_{\mathrm{a}}\right)^{1 / 2} \mathrm{u}_{\mathrm{s}} \mathrm{ds}
$$

The local rate of entrainment increases as the jet leaves the momentum-dominated region and enters a region where the effects of the buoyancy become more pronounced. The local coefficient of entrainment is a function of the local Froude number (or local Richardson number) for the case when the jet is injected horizontally (Priestley and Ball, 1955; Davidson et al., 2002), the local entrainment coefficient ( $\alpha$ ) can be written as:

$$
\begin{aligned}
& \alpha=\alpha_{j}+\left(\alpha_{p}-\alpha_{j}\right)\left(\frac{F_{p} \sin \theta}{F_{s}}\right)^{2} \\
& \operatorname{Fr}_{s}=\frac{u_{s}}{\sqrt{\left(\rho_{a}-\rho_{g}\right) / \rho_{g} g b}}
\end{aligned}
$$

This formula allows the entrainment coefficient $(\alpha)$ to be determined along the jet trajectory when there is either a jet or a plume. The entrainment coefficient varies from $\alpha_{j}$ to $\alpha_{p}$ during the transition from jet-like to plume-like. Ficher et al., 1979; Rodi, 1982 summarized much of the work on the entrainment hypothesis and proposed the values of $\alpha_{j}=0.052 \pm 0.003$ for the pure jet and $\alpha_{p}=0.0833 \pm 0.0042$ for the pure plume. The 
entrainment rate of a plume is greater than that of a jet and the entrainment rate of a buoyant jet is in between the two. The plume dependent constant $\operatorname{Fr}_{p}$ has a value that varies between 3.4 and 3.7 .

\section{Mathematical modelling}

The jet integral method proceeds by making use of the boundary-layer nature of the flow and by integrating all terms of the governing equations of motion across the crosssectional plane $\int() \mathrm{dA}$ in which $\mathrm{dA}=\operatorname{rdrd} \varphi$. For the given axisymmetric profiles, the integration amounts to $2 \pi \int_{0}^{b}() d r$. The 'jet radius' $\mathrm{b}$ is understood in boundary-layer parlance as the 'edge of the jet' at which boundary conditions can be clearly specified or, alternatively, beyond which no further contributions to the integration should arise. The basic governing equations for the integral model are based on integrating the fundamental differential conservation equations for mass and momentum over the cross-sectional area of the jet.

\subsection{Continuity equation}

The fixed injection of gas mass flow rate $\left(\dot{\mathrm{m}}_{\mathrm{g}}\right)$ at a given submergence, can be expressed as conservation of mass flux and is given by:

$$
\dot{\mathrm{m}}_{\mathrm{g}}=\int_{0}^{2 \Pi} \int_{0}^{\mathrm{b}} \rho_{\mathrm{g}} \mathrm{u}_{\mathrm{g}} \cdot \operatorname{rdrd} \varphi
$$

The jet mass flow rate remains constant for a non-condensable gas so: 
$\frac{\mathrm{d}}{\mathrm{ds}}\left(\dot{\mathrm{m}}_{\mathrm{g}}\right)=0$

Equation (8) can be written as:

$\frac{\mathrm{d}}{\mathrm{ds}} \int_{0}^{2 \Pi} \int_{0}^{\mathrm{b}} \rho_{\mathrm{g}} \mathrm{u}_{\mathrm{g}} \cdot \operatorname{rdrd} \varphi=0$

Performing the derivative in equation (9), on account that the parameter $b(s)$ depends on $s$, it is obtained:

$2 \pi b \rho_{g} u_{s} e^{-1} \frac{d b}{d s}+2 \pi \rho_{g} u_{s} \frac{d b}{d s} \int_{0}^{b} \exp \left(-\left(\frac{r}{b}\right)^{2}\right) 2\left(\frac{r}{b}\right)^{3} d r+2 \pi \rho_{g} \frac{d u_{s}}{d s} \int_{0}^{b} \exp \left(-\left(\frac{r}{b}\right)^{2}\right) r d r=0$

Performing the integrals that appears in the second and third terms, the mass flux equation can be rewritten as:

$\left(2 \pi b \rho_{g} u_{s} I_{3}\right) \frac{d b}{d s}+\left(\pi b^{2} \rho_{g} I_{3}\right) \frac{d u_{s}}{d s}=0$

where, $I_{3}=\left(1-e^{-1}\right)$.

\subsection{The $x$-momentum flux}

The $\mathrm{x}$-component of the gas momentum flow is given, on account of equation (1) for the gas velocity, by:

$$
M_{x}=\int_{0}^{2 \pi} \int_{0}^{b} \rho_{g} u_{g}\left(u_{g} \cos \theta\right) r d r d \varphi=2 \pi \rho_{g} u_{s}^{2} \cos \theta \int_{0}^{b} \exp \left(-2 \frac{r^{2}}{b^{2}}\right) r d r
$$

Performing the integral that appears in equation (12) it is obtained: 
$\mathrm{M}_{\mathrm{x}}=\Pi \mathrm{b}^{2} \mathrm{I}_{2} \rho_{\mathrm{g}} \mathrm{u}_{\mathrm{s}}^{2} \cos \theta$

where, $\mathrm{I}_{2}=\frac{1}{2}\left(1-\mathrm{e}^{-2}\right)$ is a constant.

At sufficiently high jet velocities, a part of the liquid driven by the jet begins to move and flow in the jet direction whereas the rest of the liquid still remains stagnant. Therefore, a shear layer of thickness $(\delta)$ at the gas/liquid boundary appears. An interfacial shear stress $\left(\tau_{\mathrm{i}}\right)$ is acting at the interface between the jet flow and the liquid ambient, Fig. 3. The interfacial shear stress tends to increase with the increasing of the superficial gas velocity.

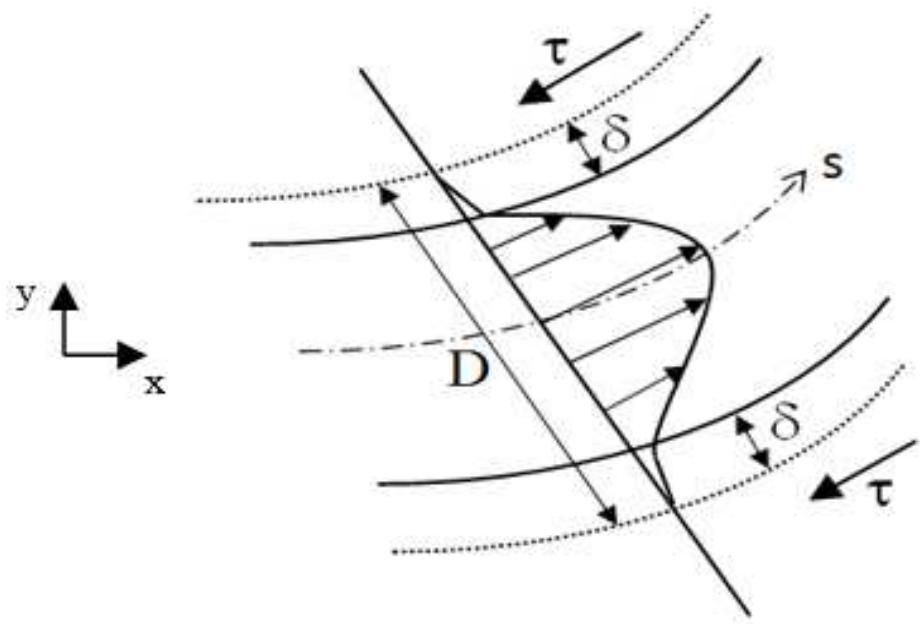

Fig. 3. Schematic diagram shows the interfacial shear stress acting at the interface between the gas jet and liquid ambient

The interfacial shear stress depends on the interfacial friction factor $\left(f_{i}\right)$, jet density and the square of the relative velocity between the average jet velocity and the interface one. 
The following correlations were proposed by Wallis, 1970 to determine the interfacial shear stress:

$$
\begin{aligned}
& \tau_{\mathrm{i}}=\mathrm{f}_{\mathrm{i}} \frac{1}{2} \rho_{\mathrm{g}}\left(\overline{\mathrm{u}}_{\mathrm{g}}-\overline{\mathrm{u}}_{\mathrm{li}}\right)^{2} \\
& \overline{\mathrm{u}}_{\mathrm{g}}-\overline{\mathrm{u}}_{\mathrm{li}} \cong \overline{\mathrm{u}}_{\mathrm{g}}
\end{aligned}
$$

where, $\overline{\mathrm{u}}_{\mathrm{g}}$ and $\overline{\mathrm{u}}_{\mathrm{li}}$ are the mean gas core jet velocity and the interfacial liquid velocity respectively. However, $\overline{\mathrm{u}}_{\mathrm{li}}$ is sufficiently small to be neglected in comparison to $\overline{\mathrm{u}}_{\mathrm{gi}}$. The mean gas velocity can be calculated as:

$\bar{u}_{g}=\frac{1}{\pi b^{2}} \int_{0}^{b} u_{g} 2 \pi r d r=\frac{1}{\pi b^{2}} \int_{0}^{b} u_{s} e^{-\left(\frac{r^{2}}{b^{2}}\right)} 2 \pi r d r=u_{s} I_{3}$

where, $\overline{\mathrm{u}}_{\mathrm{g}}$ is the mean jet gas velocity at the jet cross section. The interfacial friction factor $\left(f_{i}\right)$ is crucial in the determination of the interfacial shear stress, which strongly influences the loss of momentum of the jet. The interfacial friction factor is given by the following expression:

$$
\mathrm{f}_{\mathrm{i}}=\mathrm{c}_{1} \mathrm{R}_{\mathrm{em}}^{-\mathrm{c}_{2}}\left(1+360 \frac{\delta}{\mathrm{D}}\right)
$$

where $c_{1}$ and $c_{2}$ have constants values of 0.079 and 0.25 respectively. The corrected jet Reynolds number $\operatorname{Re}_{\mathrm{m}}$ is defined as:

$$
R e_{m}=\frac{\rho_{g} \bar{u}_{g} D}{\mu_{g}}=\frac{\rho_{g} \bar{u}_{g} 2 b}{\mu_{g}}=\frac{2 \rho_{g} u_{s} I_{3} b}{\mu_{g}}
$$


where, $\mu_{\mathrm{g}}$ is the gas dynamic viscosity $\left(\mu_{\mathrm{g}}=1.983 \times 10^{-5} \mathrm{~kg} / \mathrm{ms}\right)$, D is the hydraulic diameter of the jet flow ( $\mathrm{D}=4 \mathrm{~A} / \mathrm{p}=2 \mathrm{~b}$ ), and $\delta$ is the liquid perturbed region thickness given by (Wallis, 1970):

$\delta=\mathrm{f}_{2} \mathrm{D}\left(1-\mathrm{f}_{3} \mathrm{R}_{\mathrm{em}}^{\mathrm{f}_{4}}\right)$

where, $f_{3}=2.5 \times 10^{-3}$ and $f_{4}=0.5$ are constants. And $f_{2}$ is variable that has two values depending on the jet region, being 1 in the momentum region (from the nozzle exit to the transition point) and 0.04 for the buoyant region (starting from the transition point to a maximum point in which the jet can arrive). If the entrainment becomes important then according to Wallis the density of the vapor core $\rho_{g}$ in equation (14) must be substituted by the average density of vapor core including entrainment (Collier 1981). The entrainment can be calculated with recent correlations obtained by Berna et al (2014, 2015).

Substituting Equations (17, 18, and 19) into Equation (14) and multiplying by the jet contact area per unit length $(2 \pi b)$, the total interfacial shear force per unit length is given by:

$\tau_{\mathrm{it}}=\mathrm{c}_{1} \Pi b \rho_{\mathrm{g}}\left(\mathrm{u}_{\mathrm{s}} \mathrm{I}_{3}\right)^{2}\left(1+360 \frac{\delta}{\mathrm{D}}\right)\left[\mathrm{R}_{\mathrm{em}}\right]^{-\mathrm{c}_{2}}$

The interfacial shear force per unit length in the $\mathrm{x}$ and $\mathrm{y}$ directions is given by:

$$
\begin{gathered}
\tau_{\text {itx }}=\tau_{\mathrm{it}} \cos \theta \\
\tau_{\text {ity }}=\tau_{\mathrm{it}} \sin \theta
\end{gathered}
$$


Some flying water droplets with a velocity less than the velocity of the jet are entrained into the jet. These water droplets have a small value of momentum per unit mass. In the present study, the total momentum of the water droplets was calculated as the mass flow rate of water droplets entrained per unit length $\left(\dot{\mathrm{m}}_{\mathrm{d}}\right)$ multiplied by the velocity of entrained water droplets in the gas jet $\left(\mathrm{u}_{\mathrm{d}}\right)$ as:

$\mathrm{M}_{\mathrm{dt}}=\dot{\mathrm{m}}_{\mathrm{d}} \mathrm{u}_{\mathrm{d}}$

where, $M_{d t}$ is the total momentum of the water droplets per unit length. The mass of the water droplets $\dot{\mathrm{m}}_{\mathrm{d}}$, it was observed from the experiments that was about $20 \%$ of the entrainment mass flow rate per unit length.

$\dot{\mathrm{m}}_{\mathrm{d}}=\mathrm{f}_{\mathrm{e}} \dot{\mathrm{m}}_{\mathrm{e}}$

where, $\dot{\mathrm{m}}_{\mathrm{e}}=\mathrm{dE} / \mathrm{ds}$

Satoshi [50] studied experimentally the gas jets injected in water ambient and he measured experimentally the velocity of the water droplets $\left(u_{d}\right)$. He concluded that the water droplet velocity $\left(u_{d}\right)$ was around $1 / 30 \sim 1 / 60$ of the injected velocity of the gas at the nozzle exit $\left(\mathrm{u}_{0}\right)$, and that increased when increasing the jet pressure and it is larger than the entrainment velocity $\left(\mathrm{u}_{\mathrm{e}}\right)$ :

$\mathrm{u}_{\mathrm{d}}=\mathrm{f}_{\mathrm{d}} \mathrm{u}_{0}$

The momentum of the water droplets entrained per unit length in the $\mathrm{x}$ and $\mathrm{y}$-direction is given by:

$\mathrm{M}_{\mathrm{dx}}=\mathrm{M}_{\mathrm{dt}} \cos \theta$ 
$\mathrm{M}_{\mathrm{dy}}=\mathrm{M}_{\mathrm{dt}} \sin \theta$

where, $M_{d x}$ is the entrainment momentum in the $\mathrm{x}$-direction per unit length and $M_{d y}$ is the entrainment momentum in the y-direction per unit length. The change of the $\mathrm{x}$ momentum gas flux per unit length can be calculated by:

$\frac{\mathrm{dM}_{\mathrm{x}}}{\mathrm{ds}}=-\tau_{\mathrm{itx}}-\mathrm{M}_{\mathrm{dx}}$

The change of the $\mathrm{x}$-momentum gas flux per unit length is given by:

$2 \Pi \rho_{\mathrm{g}} \mathrm{u}_{\mathrm{s}} \mathrm{b}^{2} \mathrm{I}_{2} \cos \theta \frac{\mathrm{du} \mathrm{s}_{\mathrm{s}}}{\mathrm{ds}}+2 \Pi \rho_{\mathrm{g}} \mathrm{u}_{\mathrm{s}}^{2} \mathrm{bI} \mathrm{I}_{2} \cos \theta \frac{\mathrm{db}}{\mathrm{ds}}-\Pi \rho_{\mathrm{g}} \mathrm{u}_{\mathrm{s}}^{2} \mathrm{~b}^{2} \mathrm{I}_{2} \sin \theta \frac{\mathrm{d} \theta}{\mathrm{ds}}=-\tau_{\mathrm{ix}}-\mathrm{M}_{\mathrm{dx}}$

\subsection{The $y$ - momentum flux}

In horizontal buoyant jets, the jet axis is deflected upwards because of the increase of vertical momentum flux due to the action of the buoyancy force. The buoyancy force is acting on the jet vertically, which is equal to the rate of change of y-momentum flux, shear force and momentum of water entrained. The jet y-momentum flux is given by:

$\mathrm{M}_{\mathrm{y}}=\int_{0}^{2 \Pi} \int_{0}^{\mathrm{b}} \rho_{\mathrm{g}} \mathrm{u}_{\mathrm{g}}\left(\mathrm{u}_{\mathrm{g}} \sin \theta\right) \operatorname{rdrd} \varphi$

The buoyancy force per unit length $(\beta)$ can be written as:

$\beta=g \int_{0}^{2 \Pi} \int_{0}^{b}\left(\rho_{a}-\rho_{g}\right) \operatorname{rdrd} \varphi=\Pi g b^{2}\left(\rho_{a}-\rho_{g}\right)$

The momentum conservation equation per unit length in the y-direction is written as:

$$
\frac{\mathrm{dM}_{\mathrm{y}}}{\mathrm{ds}}=\beta-\tau_{\text {ity }}-\mathrm{M}_{\mathrm{dy}}
$$


Substituting equations (30) and (31) into Equation (32) gives the change of the vertical momentum gas flux per unit length:

$$
2 \Pi \rho_{\mathrm{g}} \mathrm{u}_{\mathrm{s}} \mathrm{b}^{2} \mathrm{I}_{2} \sin \theta \frac{\mathrm{du} \mathrm{s}_{\mathrm{s}}}{\mathrm{ds}}+2 \Pi \rho_{\mathrm{g}} \mathrm{u}_{\mathrm{s}}^{2} \mathrm{~b} \mathrm{I}_{2} \sin \theta \frac{\mathrm{db}}{\mathrm{ds}}+\Pi \rho_{\mathrm{g}} \mathrm{u}_{\mathrm{s}}^{2} \mathrm{~b}^{2} \cos \theta \mathrm{I}_{2} \frac{\mathrm{d} \theta}{\mathrm{ds}}=\Pi g b^{2}\left(\rho_{\mathrm{a}}-\rho_{\mathrm{g}}\right)-\tau_{\mathrm{ity}}-\mathrm{M}_{\mathrm{dy}}
$$

\subsection{Geometric relations}

To determine the jet trajectory two additional equations (kinematic relations) are needed which are solved simultaneously with the previous set of equations:

$$
\begin{aligned}
& \frac{d x}{d s}=\cos \theta \\
& \frac{d y}{d s}=\sin \theta
\end{aligned}
$$

\section{Solution method}

The set of previous equations provide the first derivatives of the jet-plume parameters along the jet trajectory from the source and are solved using the same solution method as that used in the analysis of Hussain and Narang, 1984 to obtain $\mathrm{d} \theta / \mathrm{ds}$, dus $/ \mathrm{ds}$ and $\mathrm{db} / \mathrm{ds}$ from equations 10, 29 and 33:

$$
\left[\begin{array}{ccc}
C_{1} & C_{2} & C_{3} \\
M_{1} & M_{2} & M_{3} \\
E_{1} & E_{2} & E_{3}
\end{array}\right]\left[\begin{array}{c}
\frac{d \theta}{d s} \\
\frac{d u_{s}}{d s} \\
\frac{d b}{d s}
\end{array}\right]=\left[\begin{array}{c}
C_{4} \\
M_{4} \\
E_{4}
\end{array}\right]
$$

The descriptive variables are the jet width $b(s)$, the jet local angle of inclination $(\Theta)$ and the jet centerline velocity $\left(\mathrm{u}_{\mathrm{s}}\right)$. 


$$
\begin{aligned}
& \frac{d \theta}{d s}=\frac{C_{4} M_{2} E_{3}-C_{4} M_{3} E_{2}-C_{2} M_{4} E_{3}+C_{2} M_{3} E_{4}+C_{3} M_{4} E_{2}-C_{3} M_{2} E_{4}}{C_{1} M_{2} E_{3}-C_{1} M_{3} E_{2}-C_{2} M_{1} E_{3}+C_{2} M_{3} E_{1}+C_{3} M_{1} E_{2}-C_{3} M_{2} E_{1}}=f_{1}(u, b, \theta, s) \\
& \frac{d u}{d s}=\frac{C_{1} M_{4} E_{3}-C_{1} M_{3} E_{4}-C_{4} M_{1} E_{3}+C_{4} M_{3} E_{1}+C_{3} M_{1} E_{4}-C_{3} M_{4} E_{1}}{C_{1} M_{2} E_{3}-C_{1} M_{3} E_{2}-C_{2} M_{1} E_{3}+C_{2} M_{3} E_{1}+C_{3} M_{1} E_{2}-C_{3} M_{2} E_{1}}=f_{2}(u s, b, \theta, s) \\
& \frac{d b}{d s}=\frac{C_{1} M_{2} E_{4}-C_{1} M_{4} E_{2}-C_{2} M_{1} E_{4}+C_{2} M_{4} E_{1}+C_{4} M_{1} E_{2}-C_{4} M_{2} E_{1}}{C_{1} M_{2} E_{3}-C_{1} M_{3} E_{2}-C_{2} M_{1} E_{3}+C_{2} M_{3} E_{1}+C_{3} M_{1} E_{2}-C_{3} M_{2} E_{1}}=f_{3}\left(u_{s}, b, \theta, s\right)
\end{aligned}
$$

Based on the derived conservation equations the expressions for the coefficients to solve this system of equations are:

$\mathrm{C}_{1}=0, \mathrm{C}_{2}=\Pi \mathrm{b}^{2} \rho_{\mathrm{g}} \mathrm{I}_{3}, C_{3}=2 \pi b \rho_{g} u_{s} I_{3}$, and $\mathrm{C}_{4}=0$

$M_{1}=-\Pi \rho_{g} u_{s}^{2} b^{2} I_{2} \sin \theta, M_{2}=2 \Pi \rho_{g} u_{s} b^{2} I_{2} \cos \theta, M_{3}=2 \Pi \rho_{g} u_{s}^{2} b I_{2} \cos \theta$ and $M_{4}=-\tau_{i t x}-M_{d x}$

$$
\begin{aligned}
& \mathrm{E}_{1}=\Pi \rho_{\mathrm{g}} \mathrm{u}_{\mathrm{s}}^{2} \mathrm{~b}^{2} \mathrm{I}_{2} \cos \theta, \mathrm{E}_{2}=2 \Pi \rho_{\mathrm{g}} \mathrm{u}_{\mathrm{s}} \mathrm{b}^{2} \mathrm{I}_{2} \sin \theta, \mathrm{E}_{3}=2 \Pi \rho_{\mathrm{g}} \mathrm{u}_{\mathrm{s}}^{2} \mathrm{bI} \mathrm{I}_{2} \sin \theta \\
& \mathrm{E}_{4}=\Pi g b^{2}\left(\rho_{\mathrm{a}}-\rho_{\mathrm{g}}\right)-\tau_{\text {ity }}-\mathrm{M}_{\mathrm{dy}}
\end{aligned}
$$

In the above system of ODEs (Eqs. 34, 35, 37, 38 and 39) there are five unknowns i.e. the jet centerline velocity $u_{s}(s)$, the jet half-width $b(s)$, the angle of inclination $\Theta(s)$ and the coordinates $(\mathrm{x})$ and $(\mathrm{y})$ of the jet axis. The numerical model starts the integration at $s=0$. The boundary conditions are the initial values for the unknown parameters;

$$
\mathrm{x}=0, \mathrm{y}=0, \theta_{(\mathrm{s}=0)}=0, \mathrm{u}_{\mathrm{s}(\mathrm{s}=0)}=\mathrm{u}_{0}, \mathrm{~b}_{\mathrm{s}(\mathrm{s}=0)=\mathrm{d}_{\mathrm{N}} / 2}
$$

A MatLab subroutine has been developed to reproduce the sets of governing ordinary differential equations formulated for the continuity, momentum, and jet trajectory equations. Also, when integrating these equations we take into account the interfacial shear stress across the external surface of the jet, the entrainment coefficient depending 
on the Froude number and the modification to include the momentum of the water droplets entrained into the jet. The system of ODE are solved simultaneously by means of a $4^{\text {th }}$ order Runge-Kutta method, and using appropriate boundary and initial conditions to obtain the variable values along the jet path and the buoyant jet trajectory. However, the program can be run in a stand-alone mode to predict the different jet parameters, and it is embedded into the image file subsystem for the prediction of the two-dimensional jet trajectories.

\section{Experimental set-up and procedures}

The experiments were conducted in the Thermal-Hydraulic and Nuclear Engineering Research Laboratory of the Institute for Energy Engineering at Polytechnic University of Valencia, Spain. The experimental set-up consists mainly of a rectangular water tank $(1000 \times 400 \times 750 \mathrm{~mm})$ made of stainless steel sheets with transparent sidewalls for flow visualization and optical measurements as shown in Figs. 4 and 5.

A large gas tank of $0.1 \mathrm{~m}^{3}$ was located before the water tank to ensure a stable gas pressure in the test section and to acts as storage capacity during the working intervals. A set of four interchangeable stainless-steel straight tubes (nozzles) with inner diameters of 2, 3, 4 and $5 \mathrm{~mm}$ were fixed horizontally at submergence depths of 400 $\mathrm{mm}$ and $200 \mathrm{~mm}$ distance above the tank bottom. This distance ensured that the tank boundaries had minimal effects on the jet flow. A pressure regulator valve insensitive to back pressure changes was used in conjunction with the gas tank to deliver a constant mass flow rate to the injector. The free water surface of the tank was covered with a perforated flat plate to provide a constant hydrodynamic pressure and limit surface waves. 


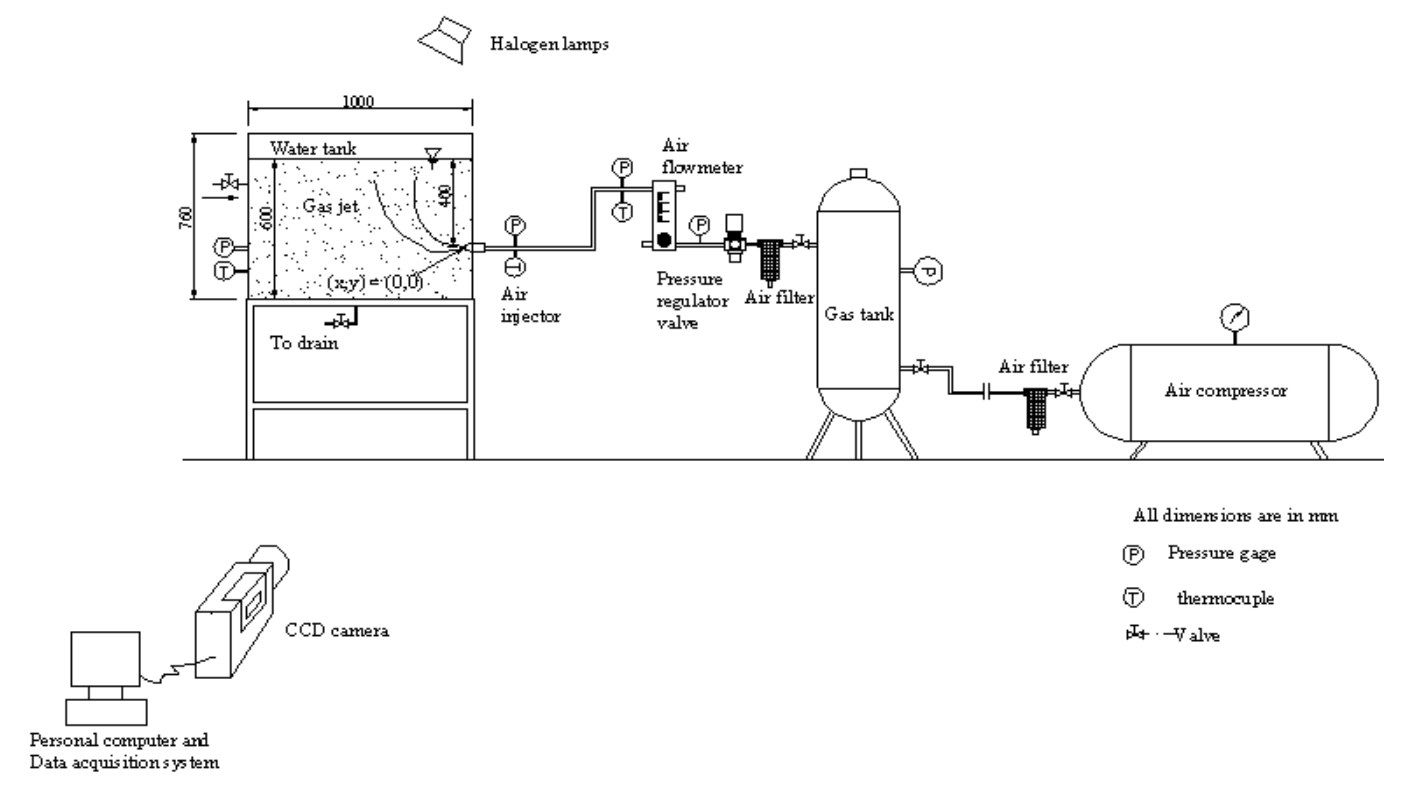

Fig. 4. Schematic diagram of the experimental set-up
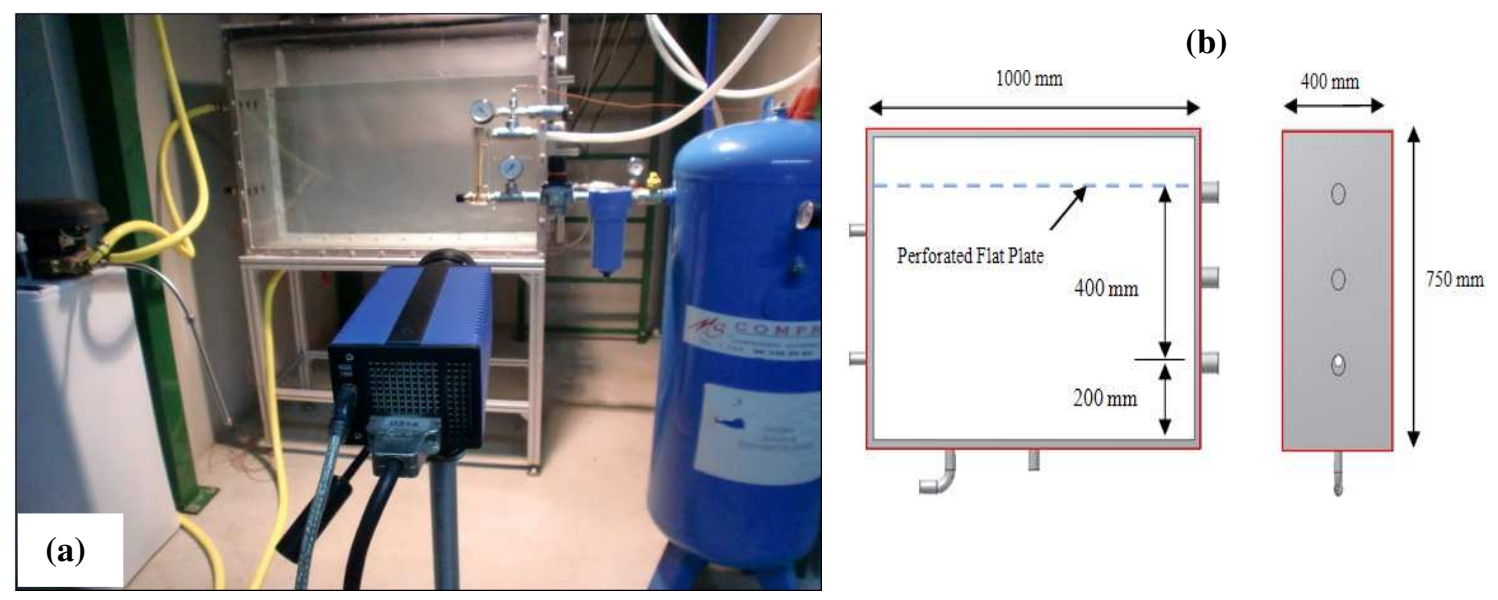

Fig. 5. Photograph showing the experimental set-up (a) and (b) shows a view with dimensions of the test section. Perforated sheets that helped to control the surface disturbances were used.

Observations of the jet parameters such as the penetration length and the interface between the jet and the water ambient were performed with direct visualization technique using a high-speed camera (CCD) and a system of illumination shown in Fig. 6. The shadowgraph images produce a projection of the gas jet onto a two-dimensional image. However, the jet images were acquired using a CCD camera PCO, model 1200 
hs. The camera was used in conjunction with a Nikon AF Nikkor 50mm f 1.8d (closest focusing: $0.45 \mathrm{~m} / 1.5 \mathrm{ft}$, filter size: $52 \mathrm{~mm}$ ) camera lens. A white-light lamp bank consisting of six $500 \mathrm{~W}$ halogen lamps arranged uniformly behind a diffusion Plexiglas sheet (to reduce the intensity of light illuminating the jet before entering the camera) was used for background illumination. The illumination system, the video camera, and the computer are combined to form the basis for the flow visualization technique, Fig. 6.

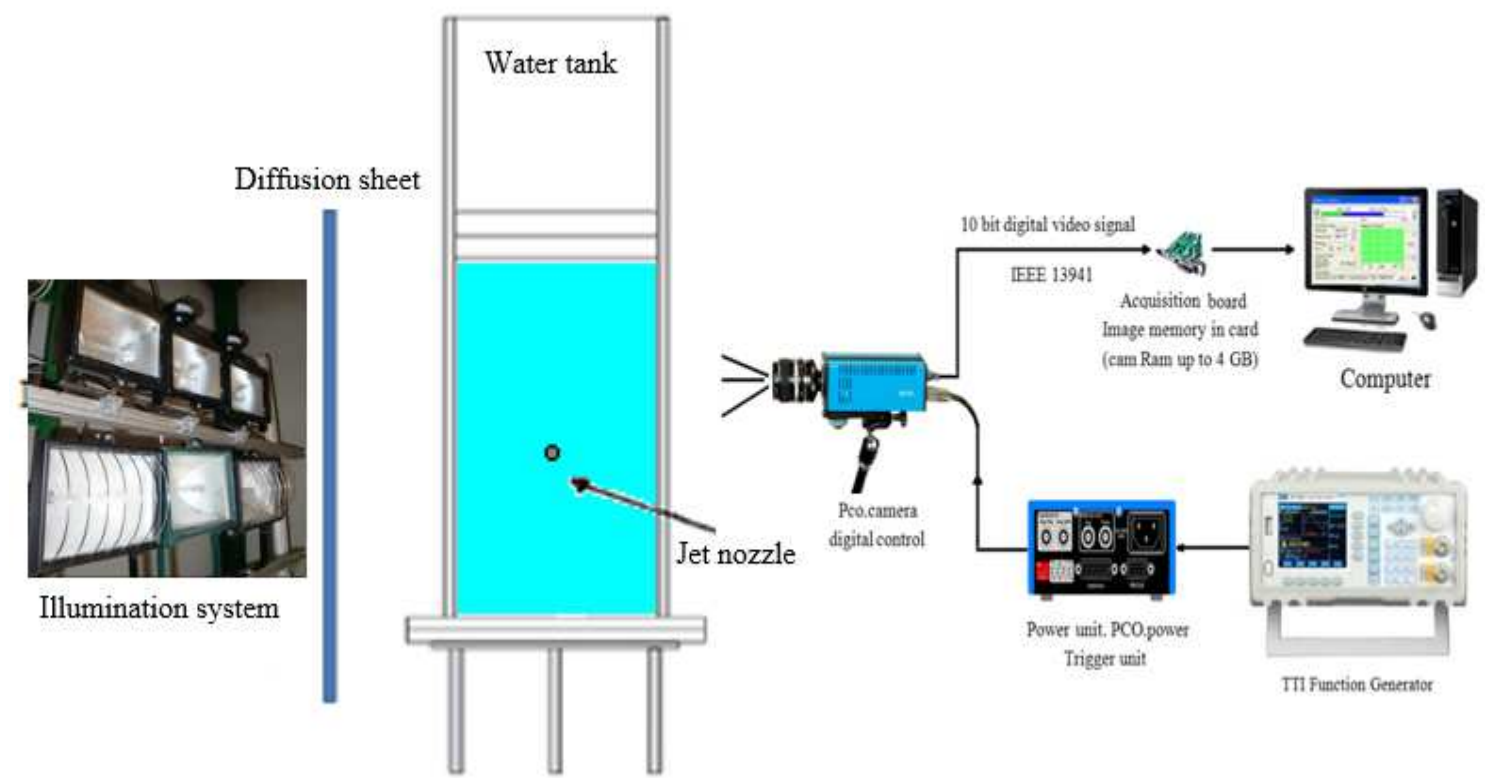

Fig. 6. Basic scheme of a visualization system with the shadow photography system The jet flow rate was measured using two different flow rotameters (Key Instruments, series FR 4500) connected in parallel with ranges of $4-50$ and $30-300 \quad 1 / \mathrm{min}$. Temperatures and pressures were measured by K-type thermocouples $\left( \pm 0.1^{\circ} \mathrm{C}\right.$ accuracy) and Druck 1400-PTX pressure transducers ( $\pm 0.15 \%$ accuracy) respectively. Several ranges of transducers and thermocouples were used to measure signals of different ranges in an effort to minimize errors. All thermocouples and pressure transducers were connected to a data acquisition system (National Instruments, model 6259, 16-bit), which works in conjunction with LABVIEW software, to monitoring and 
controlling the different magnitudes. To obtain the jet parameters in the momentum region a total of 15600 images were recorded at $1.2 \mathrm{kHz}$ sampling rate during 13 seconds for each experiment. In the buoyant region a total of 9000 images were recorded at $1 \mathrm{kHz}$ sampling rate during 9 seconds for each experiment.

\section{Measurement description and image analysis}

Flow visualization techniques are an important tool in the fluid dynamics research; they are used extensively in engineering. Especially, these techniques are widely used in the study of different phenomena associated with the two-phase flow as the present study. A series of experiments were performed using the photographic technique to record the position and motion of the entire gas jet trajectory (complete image includes the momentum and buoyancy region). Measurements on the momentum and buoyancy regions were performed to measure the jet lengths. Measurements on the entire jet have been performed to measure the two-dimensional jet trajectories and to verify and validate the mathematical model. This video was recorded at $1 \mathrm{kHz}$ with $\mathrm{CCD}$ arrays and it had a resolution of 1090x872 pixels; each centimeter corresponded to 40.5 pixels. An example of this video is shown Fig. 7.
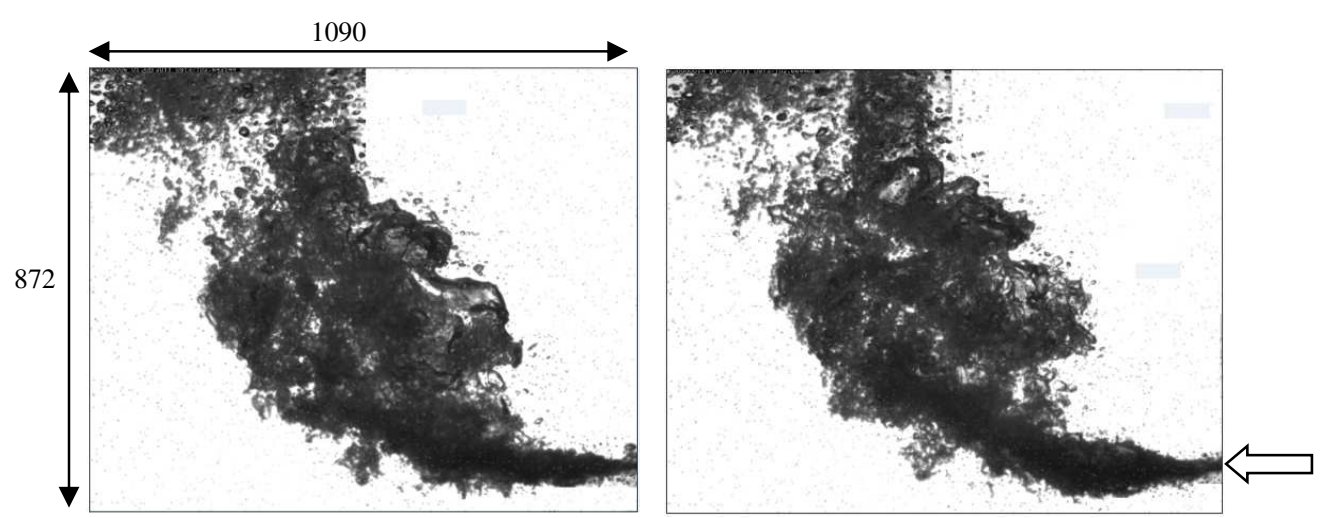

Fig. 7. Recorded shadowgraph images of the entire gas jet 
As shown from the figure, close to the jet source, jet momentum dominates. The jet spreads linearly as it entrains the ambient fluid. At downstream flow, the buoyant force acts in the vertical direction of the gravity, it changes the vertical component of the momentum at a rate equal to the buoyancy force.

The collected digital images were collected, stored and analyzed to extract the interface position, in order to measure the two-dimensional jet trajectories for different initial conditions. The same image processing technique that was used in our previous articles was performed here (Harby et al, 2014a; Harby et al, 2014b). Figs. 8. Illustrate a summary of the main structure of the program (Flow Chart) that is used in this study to record, calibrate and process the images.
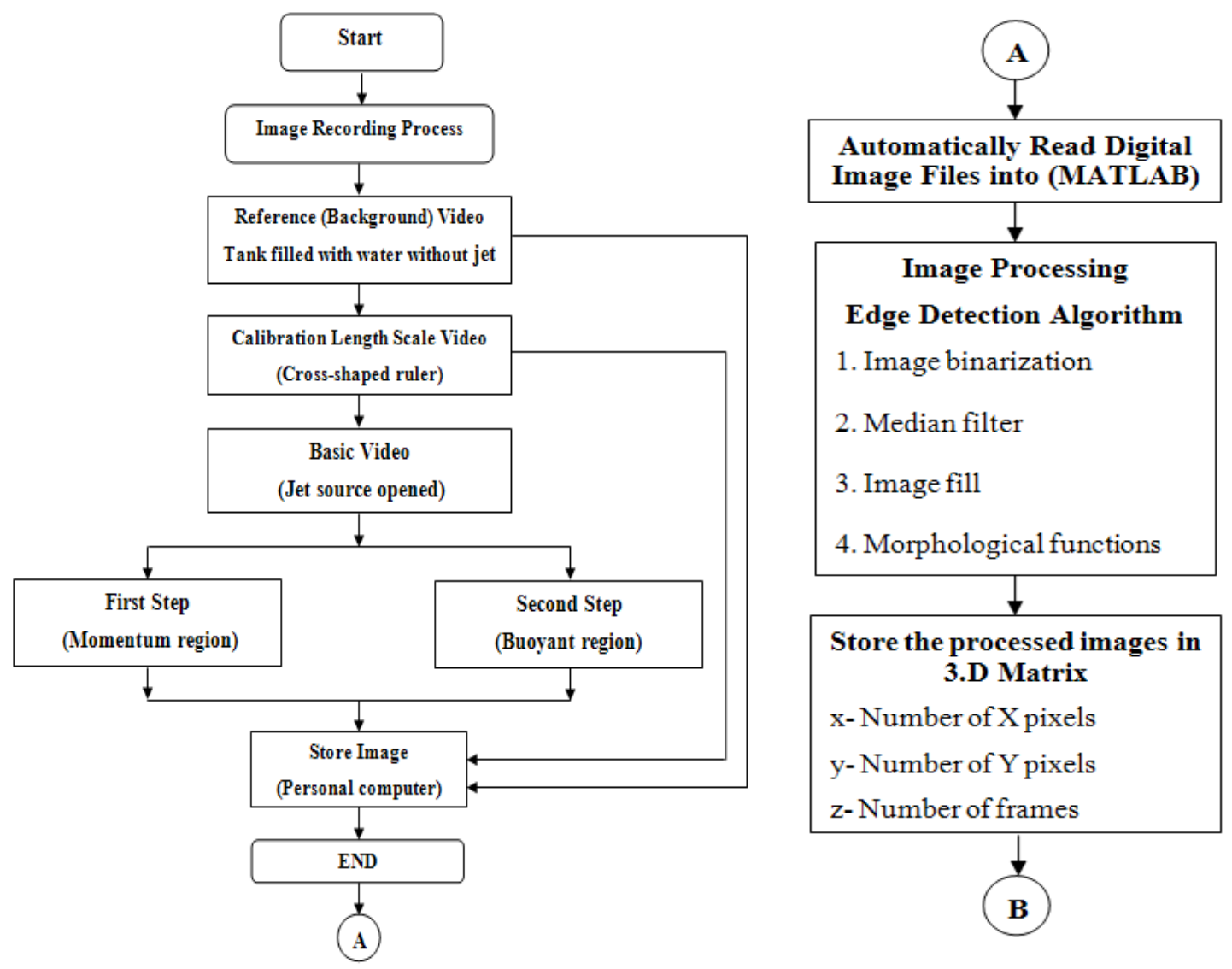

Fig. 8. Flow chart of: a) Image recording, calibration and storage steps, and b) Image processing and data storage in a 3.D matrix 
To detect the jet boundary, a routine was implemented in MATLAB consisting of several steps to perform the task of image processing as shown in Fig. 9(a-f). The dark section is the buoyant gas jet and the white section is the water ambient. At the beginning, a reference (background) with a ruler inserted into the tank videos were recorded without jet injection. These videos were used for the background correction and calibration (pixels per centimeter) procedures. Then, the jet images were recorded (9a) and converted into binary (black and white) image (9b). This image was then filtered to remove the bubbles separated from the jet interface $(9 \mathrm{c})$ and the holes within the jet were filled (9d). Finally, the jet interface was adjusted by removing any small bubbles while preserving the interfacial shape (9e). The last step consists of the edge (interface) detection, to find the perimeter of a jet image that was used for jet penetration computation (9e).

Original Image (a)

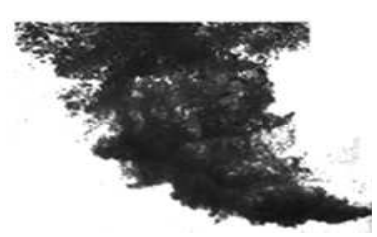

Image fill (d)

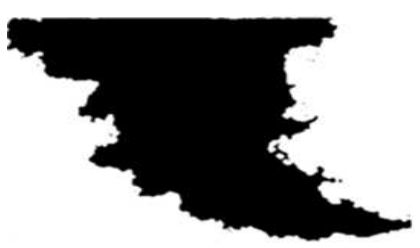

Binarization (b)

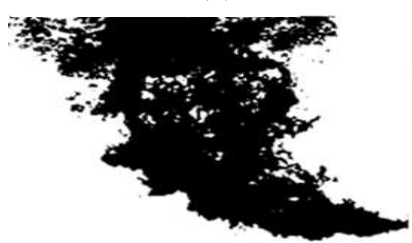

Adjusting process (e)

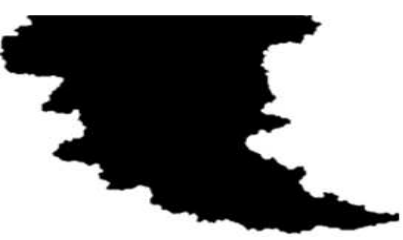

Median filter (c)

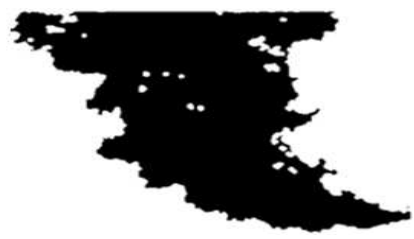

Detected perimeter (f)

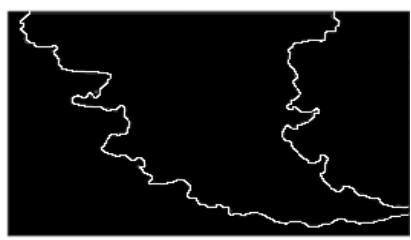

Fig. 9. Steps used to detect the jet boundary.

\section{Results and model validation}


Depending on the relative importance of the inertial and buoyancy force, the flow can be classified as jet-dominated or plume-dominated. Therefore, the strength of the jet is directly related to the value of its Froude number, $\mathrm{Fr}_{0}$.

$$
\mathrm{Fr}_{0}=\frac{\mathrm{u}_{0}}{\sqrt{\left(\rho_{\mathrm{a}}-\rho_{\mathrm{g}}\right) / \rho_{\mathrm{g}} \mathrm{gd}}} \propto \mathrm{c}_{1} \mathrm{R}_{\mathrm{ed}} \mathrm{d}_{\mathrm{N}}^{\frac{-1}{2}}
$$

For a given diameter, jets with higher Froude number have higher exit velocities and are dominated more by the initial momentum of the jet, while jets with lower Froude number have slower exit velocities and are dominated more by buoyancy.

Figs. 10(a-1) show a comparison between the simulation and experimental results (summed images) of the flow's path and spread at different Froude number and jet diameter ranges. The Figure shows the center line and upper and lower jet trajectories expressed as $\mathrm{y}=\mathrm{y}(\mathrm{x})$ plots. The experimental results for the location of the jet flow are noted with the red color symbol (gas), water ambient with blue color, and the predicted jet trajectories by black lines. As can be seen, the jet has three separated flow regimes along the downstream distance. The one close to the jet nozzle, characterized as the 'horizontal' part of the trajectory, where the flow is essentially driven by the initial horizontal jet momentum (momentum-dominated regime). The second flow regime can be characterized as the bent regime of the flow (mainly for buoyant jets with low $\mathrm{Fr}_{0}$ ), that is the result of the buoyancy force acting on the jet (buoyant dominated regime). The regime between both previous cases is a transition flow (transition regime). As the initial jet velocity $\left(\mathrm{Fr}_{0}\right)$ increase, the transition point to the buoyancy-controlled regime moves farther downstream from the nozzle exit. 

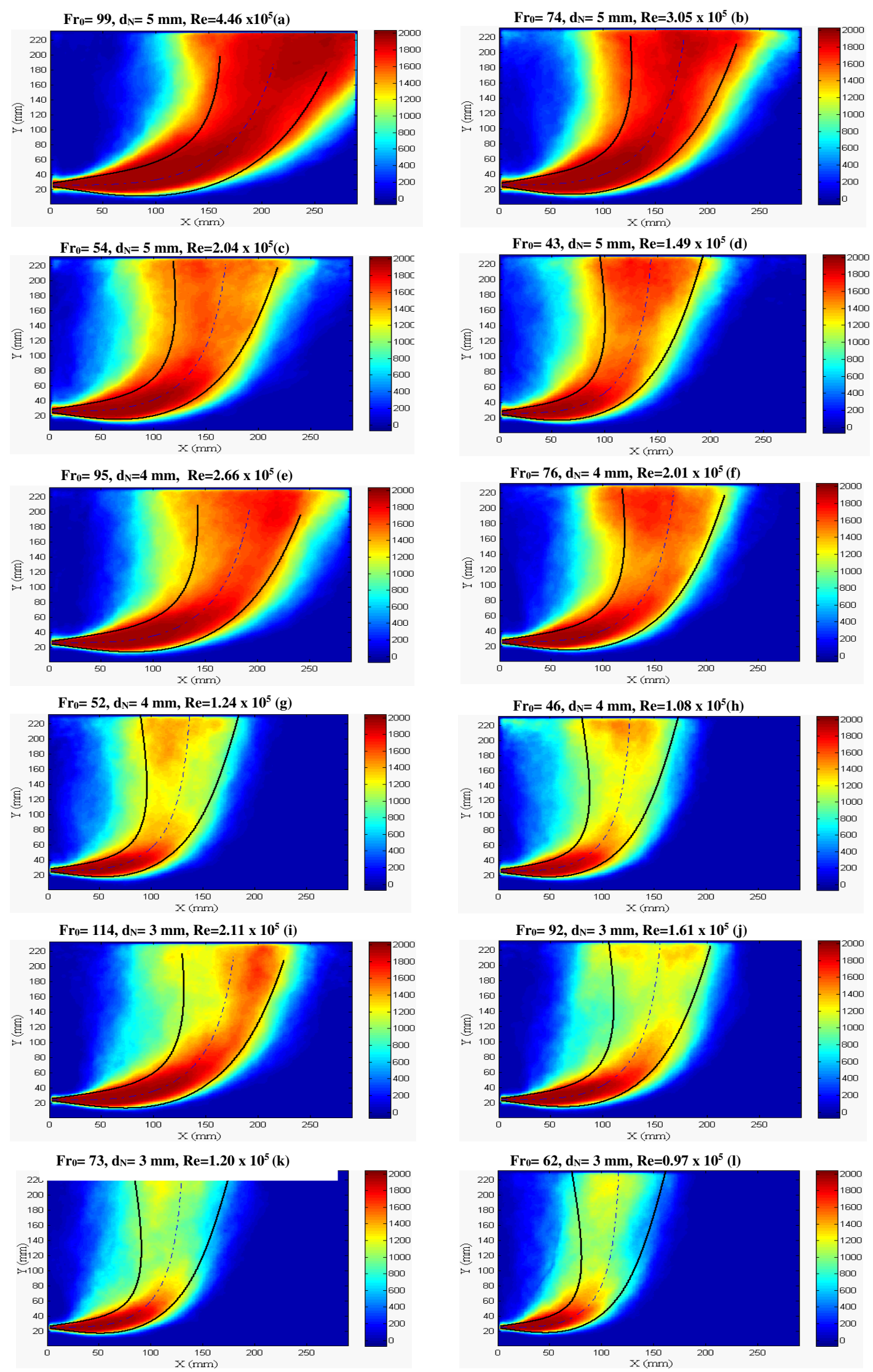

Fig. 10. Comparison of the experimental data with model prediction trajectories for horizontal buoyant jets in still ambient, dimensions in $\mathrm{mm}$. 
The numerical model predicts reasonably well the jet flow path determined from the experimental data including; jet penetration lengths, jet spreading, as well as the local angle of inclination. In all cases, the numerical model provides a satisfactory transition behavior from the momentum dominated to buoyant dominated region.

While the model appears to predict the path of the jet flow and its outer edge, the outer edge of the $5 \mathrm{~mm}$ jet diameter for the Froude number $\mathrm{Fr}_{0}=99$ is not well predicted in the buoyant region. However, the differences are relatively small. In the buoyant region, the jet edge is inherently unstable and buoyancy driven instabilities in this region generate a significant vertical flux of material out of the buoyant jet as it moves in a predominantly horizontal direction. This flux appears to destroy the typically entrained flows that one would expect to see near the edge of the jet, but in turn creates additional mixing in this region. The numerical model does not take into account the effect of the buoyancy-induced instabilities and therefore overestimate the rate of increase of the buoyancy-generated momentum flux. In addition, this difference can be attributed to the increasing of the time-scale of the turbulence. The relative importance of the initial momentum flux is thus smaller, decreasing the horizontal distance from the source to the point of maximum height.

\subsection{Jet trajectory}

Figs. 11(a-d) show a comparison between the predicted and measured jet trajectories for different initial conditions of jet diameter and Froude number. As can be seen, the jet trajectory has a strong dependence on Froude number. For fixed Reynolds number,

Froude number becomes proportional to $\mathrm{d}_{\mathrm{N}}^{-1 / 2}$, thus it means that if the nozzle diameter 
becomes smaller, the Froude number increases significantly, and consequently the jet momentum plays much more role than the buoyancy.
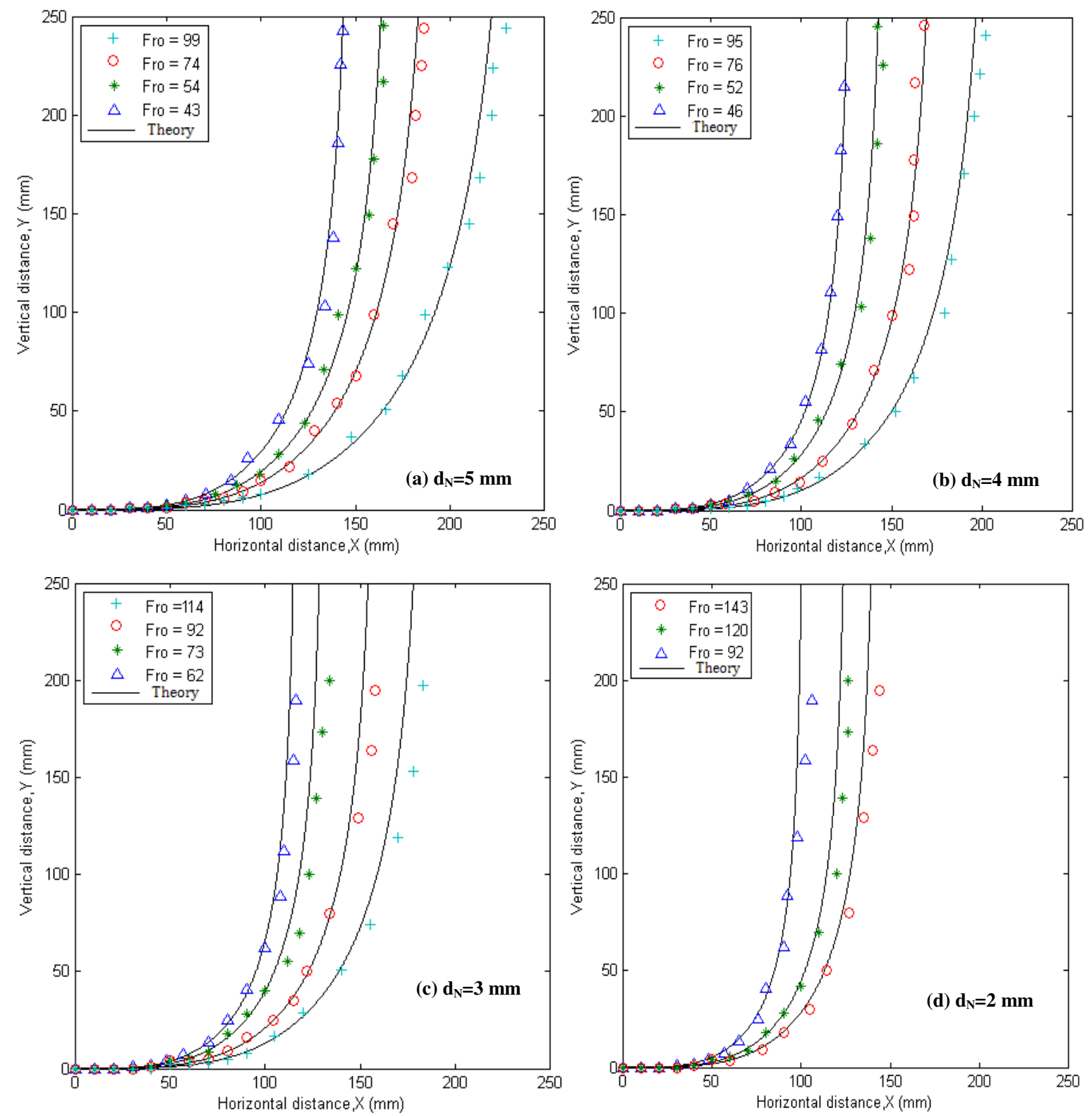

Fig. 11. Experimental and predicted center line jet trajectories for different Froude numbers and jet diameters

Again, the comparison shows that the simulation results agrees relatively well with the experimental results for the different initial conditions and jet regions. However, for higher jet Froude number values, the prediction shows small deviations from the 
experiments, particularly in the downstream region. This discrepancy is seen to be caused by the transition to turbulent flow, which should be more pronounced for higher Reynolds number flows and in the downstream region. Once the transition occurs, the bending angle begins to show a sudden decrease caused by the rapidly losing of momentum, associated with the rapid turbulent mixing with the ambient (Kima et al., 2009). Also, it is due to the increase in the interfacial motion oscillations that is experimentally correlated to a less stable jet exhibiting a greater number of pinch-off events. However, the proposed model is capable of predicting the jet trajectories from momentum to buoyancy regions by considering the Froude number and jet diameter.

\subsection{Jet penetration length}

As mentioned before, the jet length is pulsated and it varies in time along the jet axis. It should be noted that the proposed model conserves the horizontal momentum flux and therefore, from a theoretical point of view, the loss of momentum by friction in the $\mathrm{x}$ direction and the increase of momentum by buoyancy in the y-direction bend the jet trajectory and limits the jet penetration. Due to the great momentum injection, the jet shape remains straight or is slightly diverging due to the high velocity of the jet but the jet diverging angle is not as significant as suggested by Ozawa, 1986. After the jet penetrates into the liquid, buoyancy makes the jet bend vertically towards the free surface and the jet eventually becomes a plume. Therefore, the jet flow along the downstream distance can be divided into momentum jet length $\left(\mathrm{L}_{\mathrm{m}}\right)$ and buoyant jet length $\left(\mathrm{L}_{b}\right)$. Fig. 12(a,b) shows a comparison between jet penetration lengths $\left(\mathrm{L}_{\mathrm{m}}\right.$ and $\mathrm{L}_{b}$ ) observed experimentally and those predicted non-dimensionally by $\mathrm{L}_{\mathrm{Q}}$. 
The results show that the model can predict the jet lengths in both the momentum and buoyant regions. The experimental values collapse well and are consistent with the model predictions with $\pm 10 \%$ error for both jet momentum and jet buoyant penetration length.
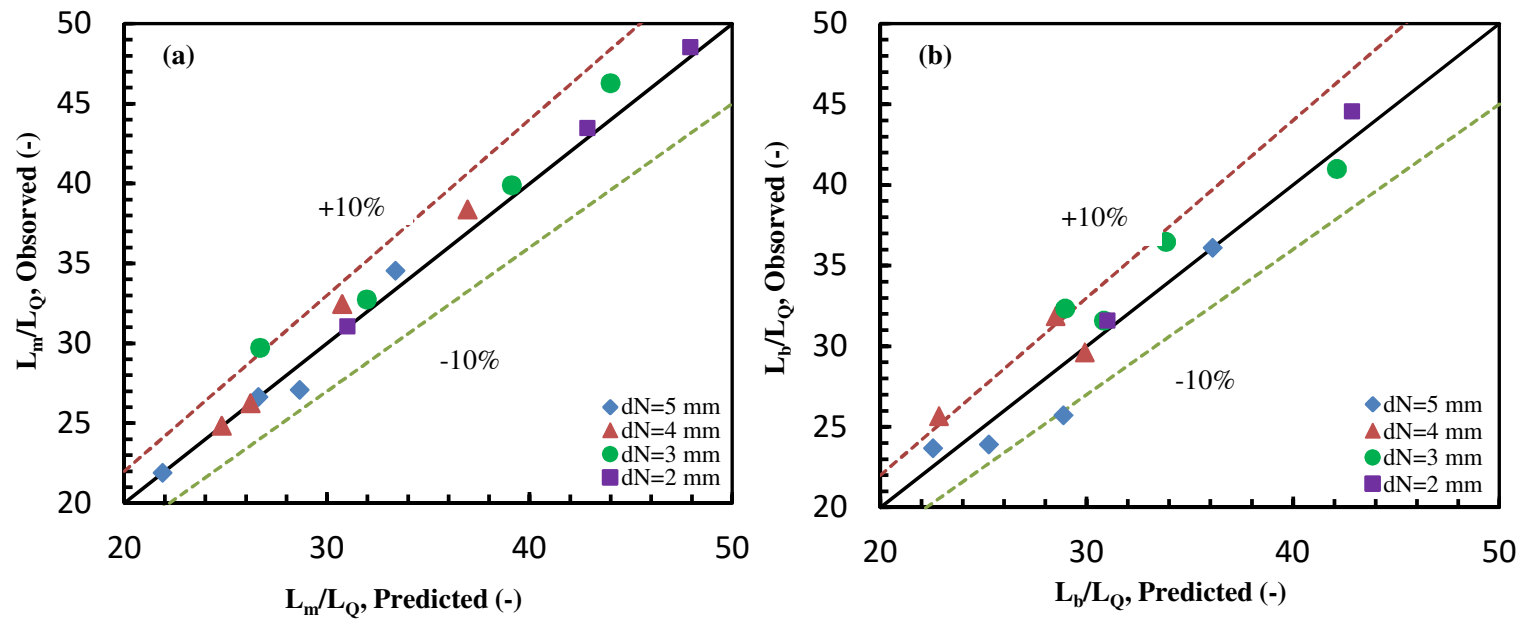

Fig. 12. Comparison between measured and predicted results of (a) momentum length $\left(\mathrm{L}_{\mathrm{m}}\right)$, and (b) buoyant jet length $\left(\mathrm{L}_{\mathrm{b}}\right)$, both normalized to the geometric length $\left(\mathrm{L}_{\mathrm{Q}}\right)$.

\subsection{Jet centerline trajectory}

After the predicted results of the numerical model are validated with the experimental results, the jet centerline trajectory, and the other jet parameters can be predicted. Figs. 13(a-d) show the centerline trajectory data, non-dimensionalised by the jet initial diameter and Froude number at different jet diameters.

The results show that depending on the value of the initial Froude number of the jet, the development of the momentum region can be significantly altered by the buoyancy forces. Trajectories of jets with high initial Froude numbers persist traveling longer distances, before they bend over to follow vertical motion. Normalized trajectories of 
the buoyant jets seem to collapse in a narrow stripe to the nozzle, which corresponds to the high values of $\mathrm{Fr}_{0}$. If the Froude number is zero as in the case of plume produced by a fire; the core of the fire is contracting and highly unstable. A swirl is often observed in such strongly buoyant flows as the surrounding fluid is drawn into the low-pressure region of the core.
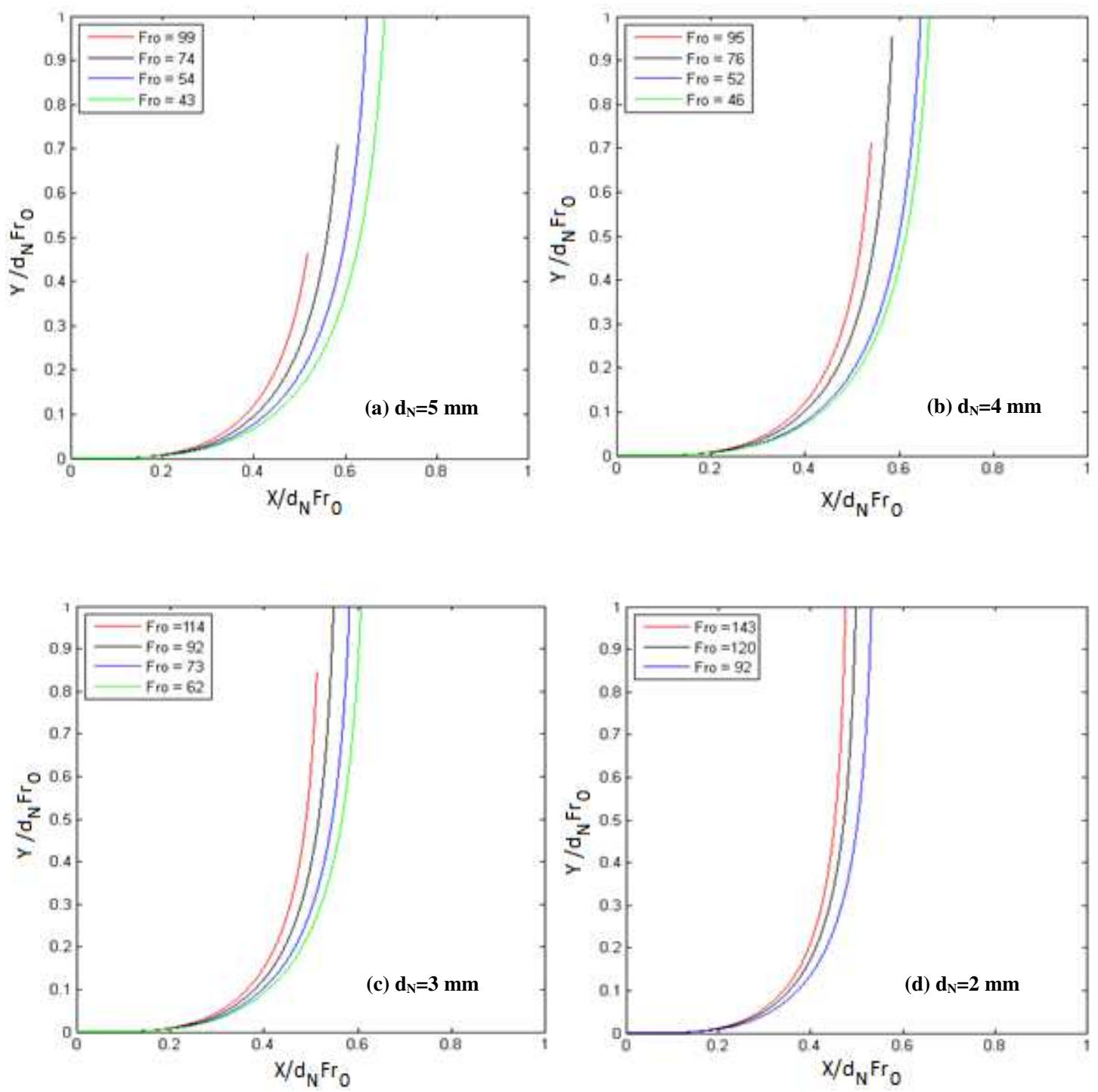

Fig. 13. Predicted normalized jet centerline trajectory at different jet diameters 


\subsection{Centerline velocity decay}

Due to the absence of measured velocity data along the jet centerline, it was decided to perform a series of numerical calculations using the proposed validated model. Fig. 14(a-d) show the decay of the normalized centerline velocity $u_{s}(s) / u_{0}$ along the nondimensional jet trajectory $\left(\mathrm{s} / \mathrm{d}_{\mathrm{N}}\right)$ for different initial conditions.

It can be seen, the normalized centerline velocity decreases in the downstream direction along the jet centerline path. As the Froude number decrease the mean axial velocity decreases as well in the downstream direction. Near the nozzle exit, the jet is in a forced convection regime with fully turbulent motion causing significant fluctuations near the jet edge. As the jet penetrates, it entrains liquid and also it expands and thus increases its volume. This causes the velocities to decrease in the streamwise direction, and the buoyancy forces become more important in the downstream direction. 

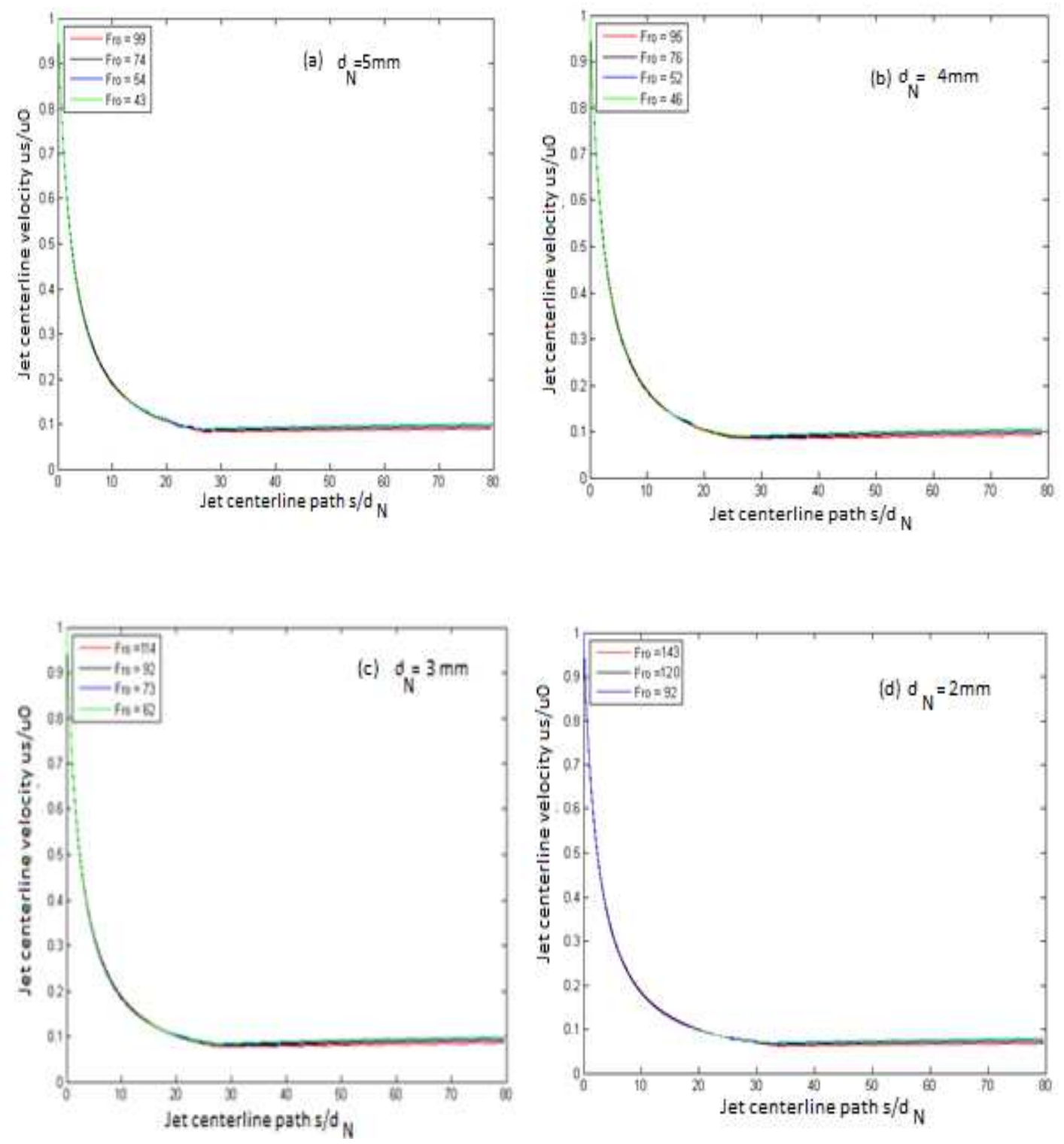

Fig. 14. Centerline velocity decay at different jet diameters and Froude numbers

\section{Conclusions}

The problem of a low-density gas jet that is injected into a higher density liquid ambient is very important in environmental and many industrial applications. The flow structure and processes are essentially unsteady and turbulent. In the present study, an integral numerical model was developed based on the conservation equations and momentum fluxes to predict the jet flow path. Verification of the model is established by comparing its results with those observed experimentally by a visualization technique with a CCD 
camera. In addition, a series of experimental tests were performed to record the momentum and buoyant jet regions in order to measure the jet lengths due to the momentum and buoyancy forces respectively.

The results from the processed images showed that, the jet flow showed a three separated flow regimes along the downstream distance namely i) momentum-dominated regime was driven by the initial horizontal jet momentum close to the jet nozzle, ii) buoyant dominated regime as a result of the buoyancy force acting on the jet, mainly dominated by the buoyancy, and iii) transition regime located between the momentum and buoyant regimes. The comparison results showed that the model predicts well the jet trajectories, the penetration lengths, the jet velocity, and the jet spread angles for a wide variety of jet initial diameters and Froude numbers. The model also predicted well the upper and lower jet trajectory as well as the jet penetration lengths $\left(\mathrm{L}_{\mathrm{m}}\right.$ and $\left.\mathrm{L}_{\mathrm{B}}\right)$ for the considered cases. The numerical model provides a satisfactory transition behavior from the momentum dominated to buoyant dominated region.

The outer upper edge of the $5 \mathrm{~mm}$ jet diameter at large Froude numbers are not well predicted in the buoyant region. However, the differences are relatively small. This can be attributed to the fact that, the jet upper edges in the buoyant region are inherently unstable due to buoyancy driven instabilities and another reason could be the increasing of the time-scale of the turbulence in this region. Since these effects increase with the injected inlet jet diameters due to the increase in the jet mass flow rate.

Therefore, the effects of large density variation and high jet velocity on the entrainment coefficient need further study in the future. The model has proved to be an efficient engineering tool for predicting the buoyant jet trajectories injected in a high-density ambient. This mean that, the calculation of the momentum losses by friction and drop entrainment are pretty well calculated with the expressions given in this paper.

\section{Acknowledgements}

The authors of this paper are indebted to the National of I+D projects MODEXFLAT ENE2013-48565-C2-1-P and ENE2013-48565-C2-2-P. 


\section{References}

Abraham, G., 1963. Jet Diffusion in Stagnant Ambient Fluid, Delft Hydraulics Laboratory Pub. 29.

Agrawal, A., and Prasad, A.K., 2003. Integral solution for the mean flow profiles of turbulent jets, plumes, and wakes. ASME Journal of Fluids Engineering 125,813-822.

Agrawal, A., Prasad, A.K., 2004. Evolution of a turbulent jet subjected to volumetric heating. Journal of Fluid Mechanics 511, 95-123.

Batchelor, G.K., 1954. Heat convection and buoyancy effects in fluids. Quarterly Journal of the Royal Meteorological Society 80, 339-358.

Berna, C., Escriva, A., Munoz-Cobo, J.L., Herranz, L.E., 2014. Review of droplet entrainment in annular flow: Interfacial waves and onset of entrainment. Progress in Nuclear Energy 74, pp 14-43.

Berna, C., Escrivá, A., Munoz-Cobo, J.L., Herranz, L.E., 2015, Review of droplet entrainment in annular flow: Characterization of the entrained droplets. Progress in Nuclear Energy 79, pp 64-86.

Bhat, G.S., and Narasimha, R.A., 1996. A volumetrically heated jet: Large-eddy structure and entrainment characteristics. Journal of Fluid Mechanics 325, 303-330.

Carlotti, P., and Hunt, G.R., 2005. Analytical solutions for turbulent non-Boussinesq plumes. Journal of Fluid Mechanics 538, 343-359. 
Carazzo, G., Kaminski, E., and Tait, S., 2006. The Route to Self-Similarity in Tutbulent Jets and Plumes. Journal of Fluid Mechanics, Vol 547, pp 137-148.

Chen, C. J., and Rodi, W., (1980), Vertical turbulent buoyant jets: A review of experimental data, HMT Science and Applications of Heat and Mass Transfer, Oxford, New York, 4 pp. 94.

Chu, V.H., and Lee, J.H., 1996. General integral formulation of turbulent buoyant jets in cross-flow, American Society of Civil Engineers (ASCE). Journal of the Hydraulics Division 122, 27-34.

Collier, J.G., 1981. Convective boiling and condensation. Edited by Mac Graw-Hill Inc. Second Edition. ISBN 0-07-011798-5

Crapper, P.F., and Baines, W.D., 1977. Non-Boussinesq forced plumes. Atmospheric Environment 11, 415-420.

Davidson, M.J., Gaskin, S., and Wood, I.R., 2002. A study of a buoyant axisymmetric jet in a small co-flow. Journal of Hydraulic Research 40, 477-489.

El-Amin, M.F., Kanayama, H., 2009. Similarity consideration of the buoyant jet resulting from hydrogen leakage. International journal of hydrogen energy 3, 58035809.

El-Amin, M.F., Shuyu, S., and Kanayama, H., 2010. Non-Boussinesq turbulent buoyant jet of a low-density gas leaks into high-density ambient. Applied Mathematics and Computation 217, 3764-3778. 
Fan, L.N., and Brook, N.H., 1969. Numerical solutions of turbulent buoyant jet problems, KH-R-18, W. M. Keck Laboratory of Hydraulic and Water Resources. California Institute of Technology, Pasadena, California.

Ficher, H.L., List, E.J., Koh, R.C., and Brooks, N.H., 1979. Mixing in inland and coastal waters. Academic Press, New York, pp. 483.

Francis, R., Jean-Louis, C., Laurent G., Philippe H., Alexandre A., François B., 2014. Structure of strongly under expanded gas jets submerged in liquids-Application to the wastage of tubes by aggressive jets. Nuclear Engineering and Design 273, 119-130.

Harby K., 2012. Experimental and theoretical study of the characteristics of submerged horizontal gas jets and vertical plunging water jets in water ambient. Ph.D., Thesis, Polytechnical University of Valencia, Spain.

Harby, K., Chiva, S., Muñoz-Cobo, J.L., 2014a. An experimental study on bubble entrainment and flow characteristics of vertical plunging water jets. Experimental Thermal and Fluid Science 57, 207-220.

Harby, K., Chiva, S., Muñoz-Cobo, J.L., 2014b. An experimental investigation on the characteristics of submerged horizontal gas jets in liquid ambient. Experimental Thermal and Fluid Science 53, 26-39.

Houf, B.B., Taylor, G., and Turner, J.S., 1956. Turbulent gravitational convection from maintained and instantaneous sources, Proceedings of the Royal Society of London, Series A. Mathematical and Physical Sciences 234, 1-23.

Houf, W.G., and Schefer, R.W., 2008. Analytical and experimental investigation of small-scale unintended releases of hydrogen. International Journal Hydrogen Energy 33, $1435-1444$. 
Hussain, N.A., and Narang, B.S., 1984. Simplified analysis of air-bubble plumes in moderately stratified environments. Journal of Heat Transfer 106, 543-551.

Ito, K., Kobayashi, S., and Tokuda, M., 1991. Mixing Characteristics of a Submerged Jet Measured Using an Isokinetic Sampling Probe. Metallurgical Transactions BProcess Metallurgy 22, 439-445.

Jirka, G.H., 2004. Integral model for turbulent buoyant jet sin unbounded stratified flows-part I: single round jet. Environmental Fluid Mechanics 4, 1-56.

Jirka, G.H., and Harleman, D.R., 1979. Stability and mixing of a vertical plane buoyant jet in confined depth. Journal of Fluid Mechanics 94, 275-304.

Kima, J.S., Yangb, W., Kimc, Y., Won, S.H., 2009. Behavior of buoyancy and momentum controlled hydrogen jets and flames emitted into the quiescent atmosphere. Journal of Loss Prevention in the Process Industries 22, 943-949.

Kotsovinos, N.E., 1975. A study of the entrainment and turbulence in a plane buoyant jet, Ph.D. Thesis, California Institute of Technology, Pasadena.

Liang, H.u., Yingnan, S., Wenyu, C., Xin, F., 2016. Experimental investigation on submerged gas-liquid mixture injection into water through a micro-channel. Int. J. Multiphase Flow 83, 39-50.

List, E. J., 1982. Turbulent jets and plums. Annual Review of Fluid mechanics 14, 198212.

List, E.J., and Imberger, J., 1973. Turbulent entrainment in buoyant jets and plumes. Journal of Hydraulic Division 99, 1461-1474. 
List, E.J., Fischer, H.B., Koh, R.C., Imberger, J., and Brooks, N.H., 1979, Mixing in inland and coastal waters, Academic Press.

Loth, E., and Faeth, G.M., 1989. Structure of Underexpanded Round Air Jets Submerged in Water. International Journal of Multiphase Flow 15,589-603.

Mathew. J., Basu, A.J., 2002. Some Characteristics of a Cylindrical Turbulence Boundary Layer, Physics of Fluids, Volume 14, Number 7.

McNallan, M.J., and King, T.B., 1982. Fluid-Dynamics of Vertical Submerged Gas Jets in Liquid-Metal Processing Systems. Metallurgical Transactions B-Process Metallurgy $13,165-173$.

Mori, K.Y., Ozawa, and Sano, M., 1982. Characterization of Gas-Jet Behavior at a Submerged Orifice in Liquid-Metal. Transactions of the Iron and Steel Institute of Japan $22,377-384$.

Morton, B.R., 1965. Modelling fire plumes, In: $10^{\text {th }}$ international symposium on combustion 973-82.

Muellenhoff, W.P., Soldate, J.A., Baumgartner, D.J., Schuldt, M.D., Davis, L.R., and Frick, W.E., 1985. Initial mixing characteristics of municipal discharges, Vol. I and II, EPA-600/3-85-073a. United States Environmental Protection Agency, Newport, Oregon.

Ozawa, Y., and Mori, K., 1986. Effect of physical-properties of gas and liquid on bubbling jetting phenomena in gas injection into liquid. Transactions of the Iron and Steel Institute of Japan 26, 291-297. 
Pantokratoras, A., 1998. Horizontal penetration of inclined thermal buoyant water. International communications in heat and mass transfer 25, 561-569.

Priestley, C.H., and Ball, F.K., 1955. Continuous convection from isolated source of heat Quarterly. Journal of the Royal Meteorological Society 81, 144-157.

Ricou, F.P., and Spalding, D.B., 1961. Measurement of entrainment by axi-symmetrical turbulent jets. Journal of Fluid Mechanics 11, 21-31.

Rodi, W., 1982. Turbulent buoyant jets and plumes, The Science and Applications of Heat and Mass Transfer, reports, reviews and computer programs. 6, Pergamon Press, New York, N.Y.

Rouse, H., Yih, C.S., and Humphreys, H.W., 1952. Gravitational convection from a boundary source. Tellus 4, 201-210.

Steward, F.R., 1970. Prediction of the height of turbulent diffusion buoyant flames. Combust Science Technology 2, 203-12.

Taib, I.M., 2015. In-water injection of high-pressure pulsed gas jet: A simple analytical tool for direct injection of gaseous fuels in automotive engine. Fuel 160, 386-392.

Taylor, G.I., 1958. Flow Induced by jets. Journal Aero Science 25, 464-465.

Turner, J.S., 1986. Turbulent entrainment: The development of the entrainment assumption, and its application to geophysical flows. Journal of Fluid Mechanics 173, $431-471$.

Wallis, G.B., 1970. Annular Two-Phase Flow, Part 1: A Simple Theory, Transactions of the ASME. Series D, Journal of Basic Engineering 92, 59-72. 
Wood, I.R., 1993. Asymptotic solutions and behavior of outfall plumes. American Society of Civil Engineers (ASCE). Journal of the Hydraulics Division 119, 555-580.

Woods, A.W., 1997. A note on non-Boussinesq plumes in an incompressible stratified environment. Journal of Fluid Mechanics 345, 347-356.

Xiao, J., Travis, J., and Breitung, W., 2009. Non-boussinesq integral model for horizontal turbulent buoyant round jets. Science and Technology of Nuclear Installations 2009, 1-7. 